\title{
Using a Statistical Preanalysis Approach as an Ensemble Technique for the Unbiased Mapping of GCM Changes to Local Stations
}

\author{
CRISTIÁN CHADWICK \\ Departamento de Ingeniería Hidráulica y Ambiental, Pontificia Universidad Católica de Chile, and Facultad de \\ Ciencias Forestales y de la Conservación de la Naturaleza, Universidad de Chile, Santiago, Chile
}

\section{JORGE GIRONÁS}

Departamento de Ingeniería Hidráulica y Ambiental, and Centro Interdisciplinario de Cambio Global, Pontificia Universidad Católica de Chile, and Centro Nacional de Investigación para la Gestión Integrada de Desastres Naturales, CONICYT/FONDAP/15110017, and Centro de Desarrollo Urbano Sustentable, CONICYT/FONDAP/15110020, Santiago, Chile

\section{SEBASTIÁN ViCUÑA}

Departamento de Ingeniería Hidráulica y Ambiental, and Centro Interdisciplinario de Cambio Global, Pontificia Universidad Católica de Chile, and Centro Nacional de Investigación para la Gestión Integrada de Desastres Naturales, CONICYT/FONDAP/15110017, Santiago, Chile

\section{FRANCISCO MEZA}

Centro Interdisciplinario de Cambio Global, and Facultad de Agronomía e Ingeniería Forestal, Pontificia Universidad Católica de Chile, Santiago, Chile

\section{JAMES MCPHEE}

Departamento de Ingeniería Civil, and Advanced Mining Technology Center, Facultad de Ciencias Físicas y Matemáticas, Universidad de Chile, Santiago, Chile

(Manuscript received 18 October 2017, in final form 19 July 2018)

\begin{abstract}
Accounting for climate change, GCM-based projections and their uncertainty are relevant to study potential impacts on hydrological regimes as well as to analyze, operate, and design water infrastructure. Traditionally, several downscaled and/or bias-corrected GCM projections are individually or jointly used to map the raw GCMs' changes to local stations and evaluate uncertainty. However, the preservation of GCMs' statistical attributes is by no means guaranteed, and thus alternative methods to cope with this issue are needed. This work develops an ensemble technique for the unbiased mapping of GCM changes to local stations, which preserves local climate variability and the GCMs' statistics. In the approach, trend percentiles are extracted from the GCMs to represent the range of future long-term climate conditions to which local climatic variability is added. The approach is compared against a method in which each GCM is individually used to build future climatic scenarios from which percentiles are computed. Both approaches were compared to study future precipitation conditions in three Chilean basins under future climate projections based on $45 \mathrm{GCM}$ runs under the RCP8.5 scenario. Overall, the approaches produce very similar results, even if a few trend percentiles are adopted in the GCM preanalysis. In fact, using 5-10 percentiles produces a mean absolute difference of $0.4 \%$ in the estimation of the probabilities of consecutive years under different precipitation thresholds, which is $\sim 60 \%$ less than the error obtained using the median trend. Thus, the approach successfully preserves the GCM's statistical attributes while incorporating the range of projected climates.
\end{abstract}

\section{Introduction}

Uncertainty is inherent to water resources planning and management. Typically, this planning has considered stationarity to characterize and quantify uncertainty. In 
particular, the design and operation of water infrastructure uses historical hydrometeorological records that are assumed to be representative of the future. Such an approach is used to assign costs and benefits to decisions and projects, as well as to estimate the involved system performance (Bras et al. 1983; Datta and Burges 1984; Datta and Houck 1984). But decision-making should no longer rely completely on the assumption of stationarity (Milly et al. 2008, 2015), as global change in general, and climate change in particular, are altering the behavior of hydroclimatic variables.

A widely used approach to cope with uncertainty in water resources management under stationarity has been probabilistic risk assessment, in which exceedance probabilities are given to different possible outcomes. Risk assessment has also been used in nonstationary extreme flood evaluation (Stedinger and Griffis 2011; Vogel et al. 2011; Salas et al. 2012; Obeysekera and Salas 2014; Salas and Obeysekera 2014; Read and Vogel 2015) and serves as an alternative to evaluate changes and variability in climate. Although a nonstationary risk assessment is challenging (Serinaldi and Kilsby 2015), and a probabilistic projection of climate change could mislead decisionmakers by underevaluating the real range of possible futures (Clark and Pulwarty 2003), risk assessment under deep uncertainty is possible (Shortridge et al. 2017). Hence, evaluating risk under nonstationary scenarios would give additional information and a wider view of future possible impacts, as compared to an evaluation assuming stationarity.

Climate change and its impacts on the hydrological regime and water systems have been widely studied by several authors (i.e., Downing et al. 1997; Adeloye et al. 1999; Lettenmaier et al. 1999; Fowler et al. 2005; Mondal and Wasimi 2007; Giorgi and Bi 2009; Mondal et al. 2010; Hagemann et al. 2011; Mahlstein et al. 2011; Matonse et al. 2013). These climate change impact studies typically follow a top-down approach that starts from the climate projections identified from general circulation models (GCMs) for different greenhouse gas (GHG) scenarios. These projections are downscaled to a regional or local scale and are used to run models to simulate specific impacts over different sectors, activities, or components of the environment, such as infrastructure, crops, cities, ecosystems, etc. (Wilby and Dessai 2010; Kiparsky et al. 2012).

Unfortunately, the approach depicted above is associated with an increasing cascade of uncertainty (Wilby and Dessai 2010), which makes decision-making very difficult (Hallegatte 2009). Indeed, the top-down studies that use insufficient GCMs lack the ability to quantify their contribution to the total uncertainty explained by this cascade. The consideration of just some of the
GCMs is commonly due to simplicity or to the fact that some specific GCMs have been identified locally to be suitable for climate change studies (Fowler et al. 2005). For example, Yung et al. (2011) evaluated 11 scenarios in the assessment of municipal water supply risk using only two GCMs (i.e., the most extreme ones) in addition to population forecasts and a variety of demand management programs and possible system expansions. Kim and Kaluarachchi (2009) used six GCMs to estimate an average future change when studying the impacts of climate change in the Blue Nile River. However, other studies consider a larger number of GCMs and GHG scenarios to analyze a wider range of possible future outcomes (Schaefli et al. 2007; Maurer et al. 2009). Typically, a large contribution to the uncertainty comes from the downscaling methods (Chen et al. 2011; Ouyang et al. 2014) and the GHG scenarios. In fact, the uncertainty coming from this last factor becomes more dominant in a distant future (Hawkins and Sutton 2011). Nonetheless, several authors have identified large uncertainties associated with the GCM choice (Minville et al. 2008; Hawkins and Sutton 2011; Chen et al. 2011; Teng et al. 2012; Ahmadalipour et al. 2018). Using a large number of GCMs improves the characterization of the impacts of climate change and its variability by allowing, for example, the estimation and assessment of risk or the relative probability of future scenarios, both concepts commonly used to deal with uncertainty in water management. Yet, considering a large number of GCMs to produce the different possible climate series may be beyond the capabilities of most water resource practitioners and decision-makers; thus, the development of simple approaches to treat multiple GCM projections becomes essential. Such approaches must not compromise the correct representation of both local climate and GCM projections.

In the attempt of having a suitable alternative to cope with GCM uncertainty when dealing with climate change, this paper develops an ensemble technique for the mapping of GCM changes to local stations, in which both the local climate variability and the GCMs' statistics are preserved (i.e., the technique is unbiased). The approach extracts future changes from annual precipitation and temperature time series derived from multiple GCM runs. A statistical framework combining these changes allows for using the needed trend percentiles to represent the range of future climate conditions. Finally, climatic variability is added to these trends to produce future scenarios coherent with local conditions. The methodology is applied to three different river basins located in the Mediterranean regions of Chile using 45 future climate projections run under the RCP8.5 scenario. In these applications, we extensively assess the results of our method against those obtained 

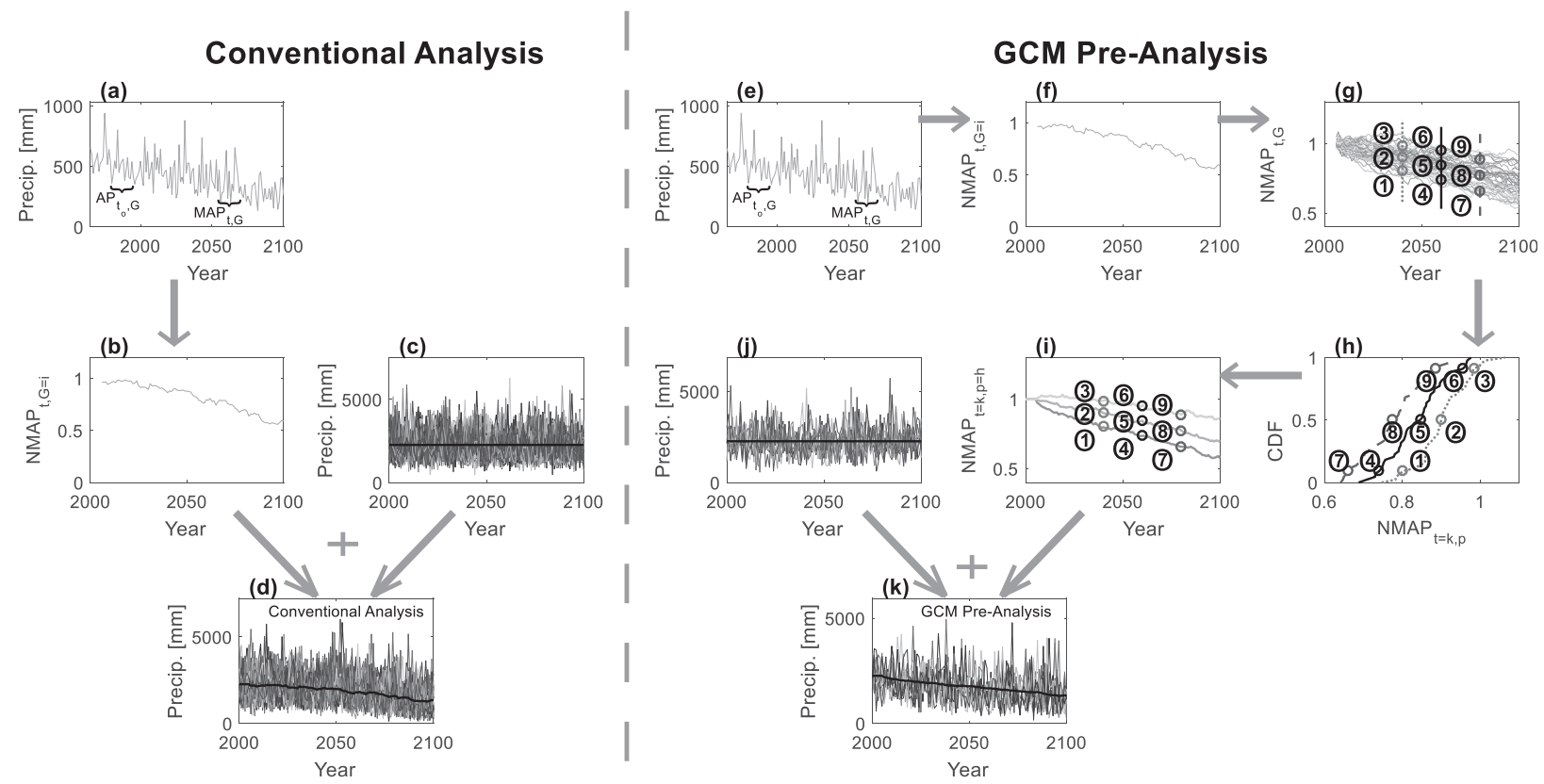

FIG. 1. Schematic representation of GCM preanalysis and conventional analysis of all GCM runs approaches. From the (b),(f) GCM precipitation, the normalized moving average $\left(\mathrm{NMAP}_{t, G}\right)$ is obtained by (a),(e) the ratio between the moving averages $\left(\mathrm{MAP}_{t, G}\right)$ and the control period average $\left(\mathrm{AP}_{t_{o}, G}\right)$. (c) The $\mathrm{NMAP}_{t, G}$ is used in the annual time series generator to obtain (d) the precipitation series with the conventional analysis approach. (g),(h) Several percentiles of $\mathrm{NMAP}_{t, p}$ are used to build (i) the GCM trends. These trends are used in (j) the annual time series generator to obtain (k) the precipitation series with the GCM preanalysis approach.

from considering individually each possible GCM output. We also compare its ability to preserve GCM and local statistics against that of more traditional approaches such as delta change, bias correction, and the use of a subset of GCMs. The paper is organized as follows: section 2 describes the approach that is able to manage GCM uncertainty for climate variability and climate change studies, whereas section 3 describes the study area and the climate time series. In section 4 the method is applied to the different case study basins, while in section 5 the main conclusions are presented.

\section{Methodology}

The proposed methodology is based on a statistical preanalysis of the GCM described in Fig. 1. This preanalysis is used to build climate time series that incorporate both trends from the GCM and natural variability. The GCM preanalysis approach is tested against the conventional analysis of all GCM runs in which each possible GCM is considered individually to produce the corresponding climate series. These series are treated statistically to estimate future climate conditions and their corresponding probability of occurrence. The ability of the proposed method to map GCM changes to local stations is also tested against three other commonly used methods (i.e., quantile mapping bias correction, the use of a subset of representative GCMs, and delta change). Further details of the climate time series generation upon the conventional analysis of all GCM runs, the preanalysis of the GCMs, and the commonly used methods are provided in sections $2 \mathrm{a}, 2 \mathrm{~b}$, and $2 \mathrm{c}$, respectively.

\section{a. Conventional analysis of all GCM runs}

The conventional analysis of all GCM runs combines two components: 1) the extraction of changes in precipitation and temperature data from the GCM and 2) the generation of annual climate series around these changes. This analysis is performed for each GCM $G$ under the RCP8.5 scenario (Moss et al. 2010), although any other radiative forcing scenarios can eventually be used.

\section{1) GCM Climate CHANGE EXTRACTION}

In this step, the three or four closest grid points of the GCM precipitation and temperature outputs (Fig. 1a) are interpolated to the gauge location using the inverse square distance method (Myers 1994). Then, the normalized moving averages in precipitation $\left(\mathrm{NMAP}_{t, G}\right)$ are obtained for the GCM for a moving time window (e.g., 25- or 30-yr window) whose last year is $t$ (Fig. 1b). $\mathrm{NMAP}_{t, G}$ measures the change in precipitation and is defined as the ratio between the GCM precipitation output moving averages $\left(\mathrm{MAP}_{t, G}\right)$ and the average from 
the control period of the GCM adopted up to the last year of this control period $t_{o}\left(\mathrm{AP}_{t_{o}, G}\right)$ :

$$
\mathrm{NMAP}_{t, G}=\frac{\mathrm{MAP}_{t, G}}{\mathrm{AP}_{t_{o}, G}}, \quad t_{o}<t<t_{f},
$$

where $t_{f}$ is the last year of the output from the GCM.

On the other hand, the temperature difference for a given GCM (DMAT $\left.{ }_{t, G}\right)$ is obtained by the difference between the GCM temperature output moving average $\left(\mathrm{MAT}_{t, G}\right)$ and the average from the control period $\left(\mathrm{AT}_{t_{o}, G}\right)$ :

$$
\mathrm{DMAT}_{t, G}=\mathrm{MAT}_{t, G}-\mathrm{AT}_{t_{o}, G}, \quad t_{o}<t<t_{f} .
$$

An analogous process is used to extract the change in the standard deviation of precipitation from the GCM group. In the case of precipitation, the normalized moving standard deviation $\left(\mathrm{NMSDP}_{t, G}\right)$ is defined for each GCM as the ratio between the GCM precipitation output moving standard deviation $\left(\mathrm{MSDP}_{t, G}\right)$ and the standard deviation from the control period $\left(\mathrm{SDP}_{t_{o}, G}\right)$ :

$$
\operatorname{NMSDP}_{t, G}=\frac{\operatorname{MSDP}_{t, G}}{\operatorname{SDP}_{t_{0}, G}}, \quad t_{o}<t<t_{f} .
$$

The temperature standard deviation difference $\left(\mathrm{DMSDT}_{t, G}\right.$ ) is obtained for each GCM by the difference between the GCM temperature output moving standard deviation $\left(\mathrm{MSDT}_{t, G}\right)$ and the standard deviation from the control period $\left(\mathrm{SDT}_{t_{o}, G}\right)$ :

$\operatorname{DMSDT}_{t, G}=\operatorname{MSDT}_{t, G}-\mathrm{SDT}_{t_{o}, G}, \quad t_{o}<t<t_{f}$.

\section{2) AnNuAl ClimAte time SERIES GENERAtor}

The second step is the generation of annual series of temperature and precipitation that incorporate local variability using a probability density function (PDF; Fig. 1c). These series are generated considering the changing climate according to the statistics of the GCMs. For each gauge of interest, the process starts by obtaining the moments (mean $\mu$, standard deviation $\sigma$, and skewness) of the annual precipitation and temperature records. These moments, or the future expected ones obtained using the historical moments and the rates of change calculated in Eqs. (1)-(4), are used to estimate the parameter set $\theta$ of any $\operatorname{PDF} f_{Y}(y, \theta)$ of the variable $Y$ (temperature or precipitation). Thus, $\theta$ will change in time according to the outcome from the GCMs, either if they are used individually to generate the climate series [section $2 \mathrm{a}(3)]$ or if they are considered jointly using the proposed ensemble approach (section $2 \mathrm{~b}$ ). Note that for precipitation we only used strictly nonnegative distributions. The $\operatorname{PDF} f_{Y}(y, \theta)$ is chosen by minimizing the Kolmogorov-Smirnov (KS) statistic of the KS test (Ayyub and McCuen 2011). Note also that the generation of temperature and precipitation series may eventually need considering and preserving the correlation between them if significant, as well as possible correlations among locations. This was not needed in the case study here presented. As an alternative, the series can be normalized to generate correlated numbers which can then be transformed back to the original variables domain using the inverse of their cumulative distribution function (Ayyub and McCuen 2011). In appendix A we propose a method for this purpose, which is applied to one of the river basins of our case study.

\section{3) INCORPORATING GCM CHANGES INTO A NONSTATIONARY ANNUAL CLIMATE SERIES GENERATOR}

We now combine the GCM precipitation and temperature changes obtained in Eqs. (1)-(4) with the annual climate series generator depicted in section $2 \mathrm{a}(2)$ for each year $t$. Thus, the resulting precipitation and temperature series incorporate both the GCM precipitation and temperature mean and standard deviation changes, as well as the natural variability coming from the standard deviation (Fig. 1d). Note that other potential sources of annual natural variability not captured by the standard deviation are not considered. Under this approach, the value of the climatic variable at any time $t$ for the GCM is obtained as

$$
Y_{t, G}=F_{Y}^{-1}(u, \theta)=F_{Y}^{-1}\left[u, \mu^{*}(t, G), \sigma^{*}(t, G)\right],
$$

where $u$ is a random uniform number $[0,1]$. Note that the values of the parameter set $\theta$ change with time, as both the mean $\mu^{*}$ and standard deviation $\sigma^{*}$ vary according to the GCM changes, while the skewness, if needed, is assumed to be constant. This approach was also adopted by Vogel et al. (2011) to incorporate trends in the return period of floods. The values of $\mu^{*}$ and $\sigma^{*}$ in Eq. (5) at any year $t$ for precipitation are calculated from the historical mean $\mu$ and standard deviation $\sigma$ and the normalized change rates calculated in Eqs. (1) and (3):

$$
\begin{aligned}
\mu^{*}(t, G) & =\mu \times \mathrm{NMAP}_{t, G} \quad \text { and } \\
\sigma^{*}(t, G) & =\sigma \times \mathrm{NMSDP}_{t, G} .
\end{aligned}
$$

For temperature, $\mu^{*}$ and $\sigma^{*}$ are obtained using the changes rates from Eqs. (2) and (4):

$$
\begin{aligned}
& \mu^{*}(t, G)=\mu+\operatorname{DMAT}_{t, G} \quad \text { and } \\
& \sigma^{*}(t, G)=\sigma+\operatorname{DMSDT}_{t, G} .
\end{aligned}
$$

Note that Eq. (5) allows the generation of annual climate variables. If intra-annual climate series were needed, 
disaggregation methods such as the $k$-nearest neighbor ( $k$-NN; Rajagopalan and Lall 1999) or the stochastic temporal disaggregation method (Thober et al. 2014) can be used. In fact, Greene et al. (2012) applied $k$-NN to disaggregate annual precipitation and temperature data into finer time scales.

\section{b. GCM preanalysis}

The GCM preanalysis considers the following steps: 1) extraction of changing rates of precipitation and temperature associated with each GCM (Figs. 1e,f), 2) grouping the changes from each GCM (Fig. 1g), 3) calculation of the empirical cumulative distribution functions (CDFs) of the GCM changes for each year (Fig. 1h), 4) construction of GCM trends using the CDFs (Fig. 1i), and 5) generation of annual climate series around each GCM trend (Fig. 1k).

To identify the long-term trends in precipitation and temperature, the resulting $\mathrm{NMAP}_{t, G}$ and $\mathrm{DMAT}_{t, G}$ time series calculated from Eqs. (1) and (2) are grouped (Fig. 1g). For each year $t$, empirical CDFs for the values of $\mathrm{NMAP}_{t, G}$ and $\mathrm{DMAT}_{t, G}$ are calculated (Fig. 1h). The trend in time associated with a given percentile or nonexceedance probability $p$ (i.e., $\mathrm{NMAP}_{t, p}$ or $\mathrm{DMAT}_{t, p}$; Fig. 1i) is given by the values of $\mathrm{NMAP}_{t, G}\left(\right.$ or $\left.\mathrm{DMAT}_{t, G}\right)$ with the same probability $p$ calculated from the CDF of each year. Hence, several trends (e.g., 25th, 50th, 75th percentiles) could be extracted and considered to analyze different possible future scenarios explicitly, in order to represent the dispersion among the group of GCM results.

An analogous process is done for the standard deviation. Thus, empirical CDFs for changes in the standard deviation of precipitation and temperature $\left(\mathrm{NMSDP}_{t, G}\right.$ and $\mathrm{DMSDT}_{t, G}$ ) calculated from Eqs. (3) and (4) are obtained. Again, different percentiles are chosen, which allows the definition of continuous trends with percentile $p\left(\mathrm{NMSDP}_{t, p}\right.$ and $\left.\mathrm{DMSDT}_{t, p}\right)$. To avoid producing climate data whose trends in average and variability are inconsistent with the GCM output, the value of $p$ is chosen for the trend of the normalized moving average in precipitation $\left(\mathrm{NMAP}_{t, p}\right)$, and it is randomly generated for the trend of the normalized moving average in standard deviation $\left(\mathrm{NMSDP}_{t, p}\right)$ after considering the average correlation between $\mathrm{NMAP}_{t, G}$ and $\mathrm{NMSDP}_{t, G}$. The same procedure is applied to temperature $\left(\mathrm{DMAT}_{t, p}\right.$ and $\left.\mathrm{DMSDT}_{t, p}\right)$. Note that we focus the subsequent assessment of our method on an independent analysis of temperature and precipitation. Were a joint analysis of these variables needed, one could also consider the correlation among the average and standard deviation of precipitation and temperature when assigning the values of $p$. This could be done by choosing the value of $p$ for $\mathrm{NMAP}_{t, p}$ and randomly generating the value of $p$ for $\mathrm{NMSDP}_{t, p}, \mathrm{DMAT}_{t, p}$, and $\mathrm{DMSDT}_{t, p}$. This process must consider the matrix with the correlations among $\mathrm{NMAP}_{t, G}, \mathrm{NMSDP}_{t, G}$, $\operatorname{DMAT}_{t, G}$, and $\mathrm{DMSDT}_{t, G}$.

The trends estimated from the GCM output are used on the annual climate series generator (Fig. 1j). Thus, the resulting climate series (Fig. 1k) is a GCM ensemble that incorporates the natural variability. The climatic variable at any year $t$ for a trend percentile in $\mu\left(p_{1}\right)$ and in $\sigma\left(p_{2}\right.$ correlates with $\left.p_{1}\right)$ is obtained as

$Y_{t, p_{1}, p_{2}}=F_{Y}^{-1}(u, \theta)=F_{Y}^{-1}\left[u, \mu^{*}\left(t, p_{1}\right), \sigma^{*}\left(t, p_{2}\right)\right]$.

Note that Eq. (10) is the same as Eq. (5), but it uses the GCM ensemble trends instead of the changes of a single GCM. The values of the parameter set $\theta$ change with time, as both the mean $\mu^{*}$ and standard deviation $\sigma^{*}$ change with $\mathrm{NMAP}_{t, p}, \mathrm{DMAT}_{t, p}, \mathrm{NMSDP}_{t, p}$, and $\mathrm{DMSDT}_{t, p}$.

\section{c. Bias correction and downscaling methods}

The GCM preanalysis capability to reproduce the raw GCM projection changes over the mean and the standard deviation of annual precipitation is also tested against a quantile mapping bias correction (Wood et al. 2002), the subset of representative GCM projections (Whetton et al. 2012), and the delta change approach (Hay et al. 2000). These three approaches are some of the most widely used to incorporate GCM statistics to climate change studies.

The quantile mapping bias correction (QMBC) was originally developed by Wood et al. (2002) and subsequently used elsewhere (e.g., VanRheenen et al. 2004; Maurer 2007; Maurer et al. 2009; Shi et al. 2018; Walton et al. 2017). Wood et al. (2004) successfully compared this method against other dynamic and statistical methods. In our work, the QMBC is applied to annual precipitation data by using a gamma-gamma transformation (Sharma et al. 2007).

The subset of GCM projections is a selection of a few raw GCMs projections that are more likely and/or have a more severe impact (Whetton et al. 2012). We selected five raw GCM projections to represent the quantiles of the GCM precipitation projection changes. The most extreme GCM mean precipitation changes (i.e., $1 \%$ and $99 \%$ percentiles) and the interquartiles (i.e., $25 \%, 50 \%$, $75 \%$ ) between the near future (2036-63) and the control period (1978-2005) were selected as representative of the entire group of GCM projections. These five GCM projections are not bias corrected.

The delta change approach, also called change factor, consists of applying the changes in the raw GCM 
projections to the historical climate data (Hay et al. 2000; Diaz-Nieto and Wilby 2005; Minville et al. 2008). For precipitation, the delta change method multiplies the historical precipitation series by the change factor associated with the mean precipitation of the raw GCM projections.

\section{Study area and climate time series}

The methodology is applied to three basins located in central Chile (Fig. 2): 1) the Limarí River basin, a semiarid Mediterranean basin in north-central Chile whose outlet is located at $30^{\circ} 43^{\prime} 51^{\prime \prime} \mathrm{S}, 71^{\circ} 42^{\prime} 01^{\prime \prime} \mathrm{W}$; 2 ) the Maipo River basin, a Mediterranean basin in central Chile whose outlet is located at $33^{\circ} 36^{\prime} 40^{\prime \prime} \mathrm{S}, 71^{\circ} 37^{\prime} 50^{\prime \prime} \mathrm{W}$; and 3) the Maule River basin, another Mediterranean basin in south-central Chile whose outlet is located at $35^{\circ} 19^{\prime} 00^{\prime \prime} \mathrm{S}, 72^{\circ} 24^{\prime} 30^{\prime \prime} \mathrm{W}$. All these basins are bordered on the west by the Pacific Ocean and on the east by the Andes Mountains.

These three basins are representative of the Mediterranean climate conditions in central Chile. Differences in annual precipitation regime are observable in basic rainfall statistics obtained from rain gauges in each basin (Table 1). Annual rainfall increases from north to south, while the annual temperature tends to decrease (Table 1). On the other hand, the value of the coefficient of variance for precipitation decreases with latitude, reflecting a less variable interannual precipitation in the south. The historical control period used in our study goes from 1978 to 2005. The duration of this period was restricted on the one side by the availability of data and the existence of a shift of the Pacific decadal oscillation that took place between 1975 and 1976 that affects the stationarity assumption (Trenberth 1990; Rosenblüth et al. 1997; Trenberth and Stepaniak 2001; Giese et al. 2002; Boisier and Aceituno 2006; Bown and Rivera 2007). On the other hand, the year 2005 corresponds to the end of a historical control period of the GCM (Taylor et al. 2012).

For this study we considered 45 climate projections of $20 \mathrm{GCMs}$ and their realizations from the phase 5 of the Coupled Model Intercomparison Project (CMIP5; Taylor et al. 2012) listed in appendix B. A weighting factor corresponding to the inverse of the number of realizations of each GCM is used for each one of the 45 GCM projections (e.g., each one of the five CanESM2 projections has a weighting factor of $1 / 5$ ). Other alternative weighting criteria could be used.

\section{Results and discussion}

In this section we evaluate the effectiveness of the GCM preanalysis strategy. For this purpose, we first validate the conventional analysis of all GCM runs as the best method to reproduce both the local climate and GCMs' statistics (section 4a). We then use this approach as the reference to assess the ability of the GCM preanalysis to reproduce the statistical moments of precipitation and temperature (section $4 \mathrm{~b}$ ). Finally, in section $4 \mathrm{c}$ we compare future precipitation and its recurrence probabilities over several years estimated using the GCM preanalysis and the conventional analysis of all GCM runs. Furthermore, we evaluate the error between both approaches by varying the number of trends considered on the GCM preanalysis.

\section{a. Reproduction of GCM precipitation changes}

The ability of the GCM preanalysis to reproduce both the precipitation from the Limarí basin and the changes of the GCM projections is compared in Fig. 3 against the results from the conventional analysis, QMBC, the subset of five GCMs, and the delta change method. The GCM preanalysis uses 45 trend percentiles of the mean, and the standard deviation trends are randomly selected after considering the correlation among them. To avoid producing results that are biased toward the GCMs with more realizations, each GCM realization is repeated $n$ times, where $n$ is the ratio between the least common multiple of the number of realizations of each GCM and the number of realizations of that specific GCM (i.e., each CanESM2 realization is considered six times, because the least common multiple of the number of realizations of each GCM is 30 and CanESM2 has five realizations).

The historical mean precipitation is well reproduced by all the methods, except the raw GCMs and the subset of five GCMs, which has not gone through bias correction (Fig. 3a). Because it uses the historical record, the delta change always reproduces the historical mean. The percentage of change of the mean precipitation for the near period (2036-63) according to the raw GCMs is well reproduced by all the methods, except the QMBC (Fig. 3b), whereas for the late period (2066-93) is well reproduced by the delta change and both the conventional analysis and the GCM preanalysis (Fig. 3c). The subset of five GCMs partially reproduces the percentage of change in the late period, while QMBC tends to overestimate the negative changes. The best method in reproducing the mean precipitation and its change is the delta change, followed closely by both the conventional analysis and the GCM preanalysis, which do not capture the exact range of change from the raw GCMs. This is explained by the fact that trend is assigned the last year of the moving window when built, which causes a time lag between the changes from the raw GCM and both methods. The subset of GCMs performs correctly in the near period, because the selection was done in this 

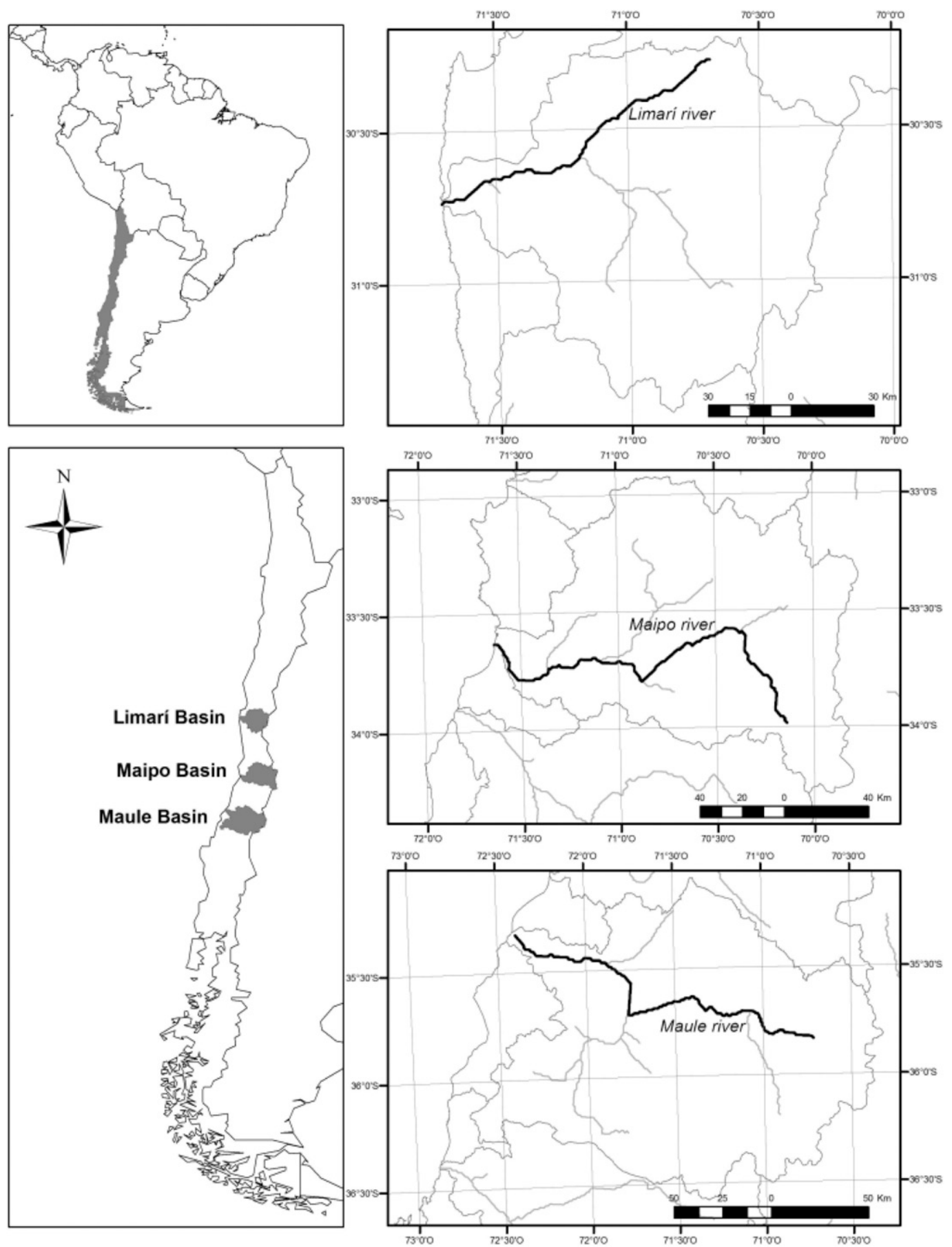

FIG. 2. The Limarí, Maipo, and Maule River basins and their geographic locations.

period, but in the late period its performance decreases. As noted also by Pierce et al. (2015), the QMBC method may significantly alter the changes projected by the raw GCMs.

The historical precipitation standard deviation is perfectly reproduced by the conventional analysis, the
GCM preanalysis, and delta change, and very well reproduced by the QMBC (Fig. 3d). The raw GCM and the GCM subset significantly underestimate the standard deviation. The percentage of change of the standard deviation for the near future (2036-63) is best reproduced by the conventional analysis followed by 
QMBC (Fig. 3e). Although the GCM preanalysis is not able to correctly represent the range of the standard deviation changes, it represents the median change very well. Finally, both the GCM subset and the delta change perform poorly. For the late period (2066-93) the conventional analysis is the best in representing the standard deviation changes (Fig. 3f). Again, the GCM preanalysis reproduces the median change well, but cannot capture the range of values correctly. All the other methods have trouble in reproducing the changes in the standard deviation.

Overall, the conventional analysis is the best method to both reproduce local climate and GCMs' statistics, followed by the GCM preanalysis. Although the GCM preanalysis does not perform as expected on the standard deviation changes, it represents the median change very well. The rest of the downscaling and/or bias correction methods have different problems in preserving the raw GCMs' changes.

\section{b. Reproduction of the climate time series moments}

Figure 4 compares GCM percentiles of the first three moments obtained from the conventional analysis and the GCM preanalysis [i.e., mean $\mu$, standard deviation $\sigma /$ coefficient of variation $(\mathrm{CV})$, and skewness] of the future climate data (precipitation and temperature) for the three basins (Limarí, Maipo, and Maule). This comparison uses the simplest alternative for the percentiles of the trends, which is adopting the same percentiles for $\mu$ and $\sigma$ trends on the GCM preanalysis. Nonetheless, this alternative may oversimplify the representation of the future climate. Note that climate data generated by using the conventional analysis have three dimensions: a GCM dimension, number of annual random realizations, and time. In this case, the moments are calculated over the random realizations and then, for each year, percentiles are estimated by building the empirical CDF over the GCMs (Fig. 4). Because in the GCM preanalysis percentiles are chosen while building trends, they are known before generating the climate data. Hence, in this case moments are estimated over the random realization for each year (Fig. 4). The selection of trend percentiles for $\mu$ and $\sigma$ in the GCM preanalysis before generating climate values, allows by construction to reproduce the same percentiles of the conventional analysis.

The mean and standard deviation of precipitation and temperature for the three basins (Fig. 4, first and second columns) of GCM preanalysis are the same as conventional analysis for the 25th, 50th, and 75th percentile. Hence, not only are future values of $\mu$ and $\sigma$ the same, but the GCM percentiles can also be chosen at the beginning, which simplifies the analysis when using the GCM preanalysis. The CV and the skewness of the 

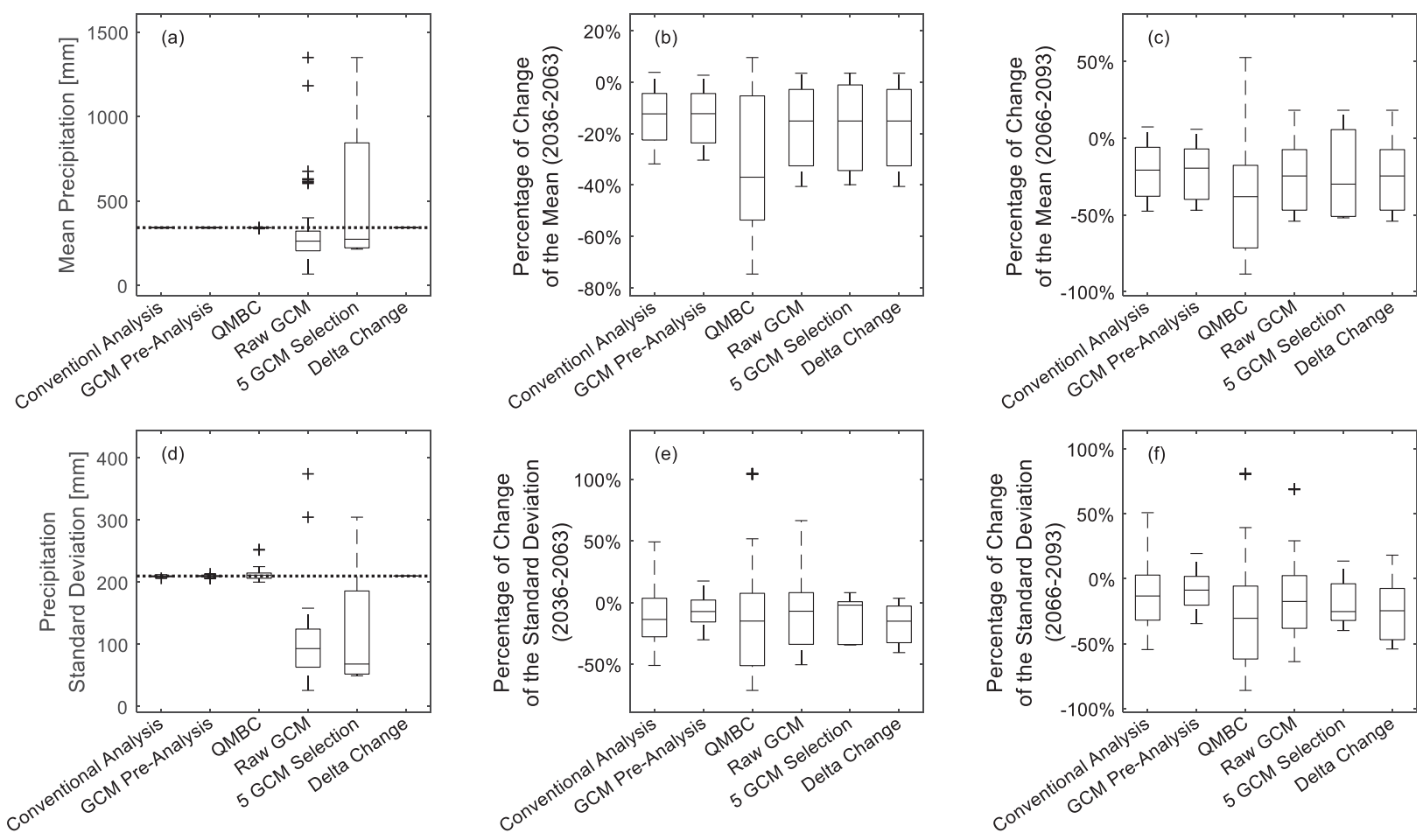

FIG. 3. Performance of different downscaling or bias correction methods in reproducing the mean and standard deviation of historical precipitation (dotted lines) and its future change (\%) for the Limarí basin.

50th percentile of precipitation are the same for GCM preanalysis and conventional analysis (Fig. 4, third and fourth columns). Such level of agreement was not obtained for the 25th and 75th percentiles, especially after the year 2050. For temperature, the behavior of CV produced by GCM preanalysis and conventional analysis is very similar (Fig. 4, third column), with minor differences being observed for the Maule basin. Finally, temperature skewness obtained from the GCM preanalysis and conventional analysis are similar although more variability is produced in the preanalysis case (Fig. 4, fourth column). Overall, the moments obtained from GCM preanalysis are quite close to the moments obtained from conventional analysis.

Because the same trend percentiles for $\mu$ and $\sigma$ were used in the GCM preanalysis shown in Fig. 4, the reproduction of moments obtained from conventional analysis is the best possible we could obtain. In reality, however, these percentiles are not necessarily the same, although they are correlated (i.e., a GCM producing a big change in the mean tends to produce a larger change in the standard deviation as well). Figure 5 presents same results as Fig. 4, but GCM preanalysis takes into account these differences between the trends for $\mu$ and $\sigma$. In this case, GCM preanalysis uses 45 equally spaced percentiles of the mean, while percentiles for the standard deviation trends are randomly selected after considering the correlation among them. GCM preanalysis moments are estimated along the dimension of the random realizations, and then the percentiles are estimated from empirical CDF over GCMs for each year (Fig. 5). Note that results from conventional analysis in Figs. 4 and 5 are the same.

For the three river basins, the 25th, 50th, and 75th percentiles of $\mu$ for precipitation and temperature of the climate generated with GCM preanalysis and conventional analysis are the same (Fig. 5, first column). The skewness in temperature is also quite similar for all three basins (Fig. 5, fourth column), whereas for precipitation, they are not alike (i.e., the values from the conventional analysis are overestimated by the preanalysis values). The preanalysis and conventional analysis $\sigma$ and the $\mathrm{CV}$ for both precipitation and temperature also differ, though in some cases the medians are similar (Fig. 5, second and third columns). The differences in $\sigma$ are partially due to random selection of trend percentiles on the GCM preanalysis, making comparison not completely fair. Note that mean is the only moment clearly changing across all three basins (Figs. 4, 5), with reductions in precipitation and increases in temperature.

\section{c. Reproduction of future precipitation}

In the previous section the effectiveness of GCM preanalysis was tested by its performance on the reproduction 

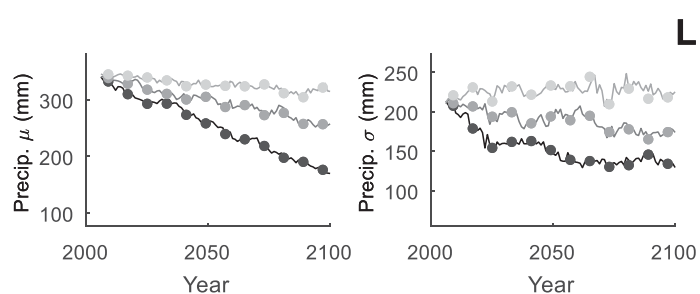

\section{Limarí}
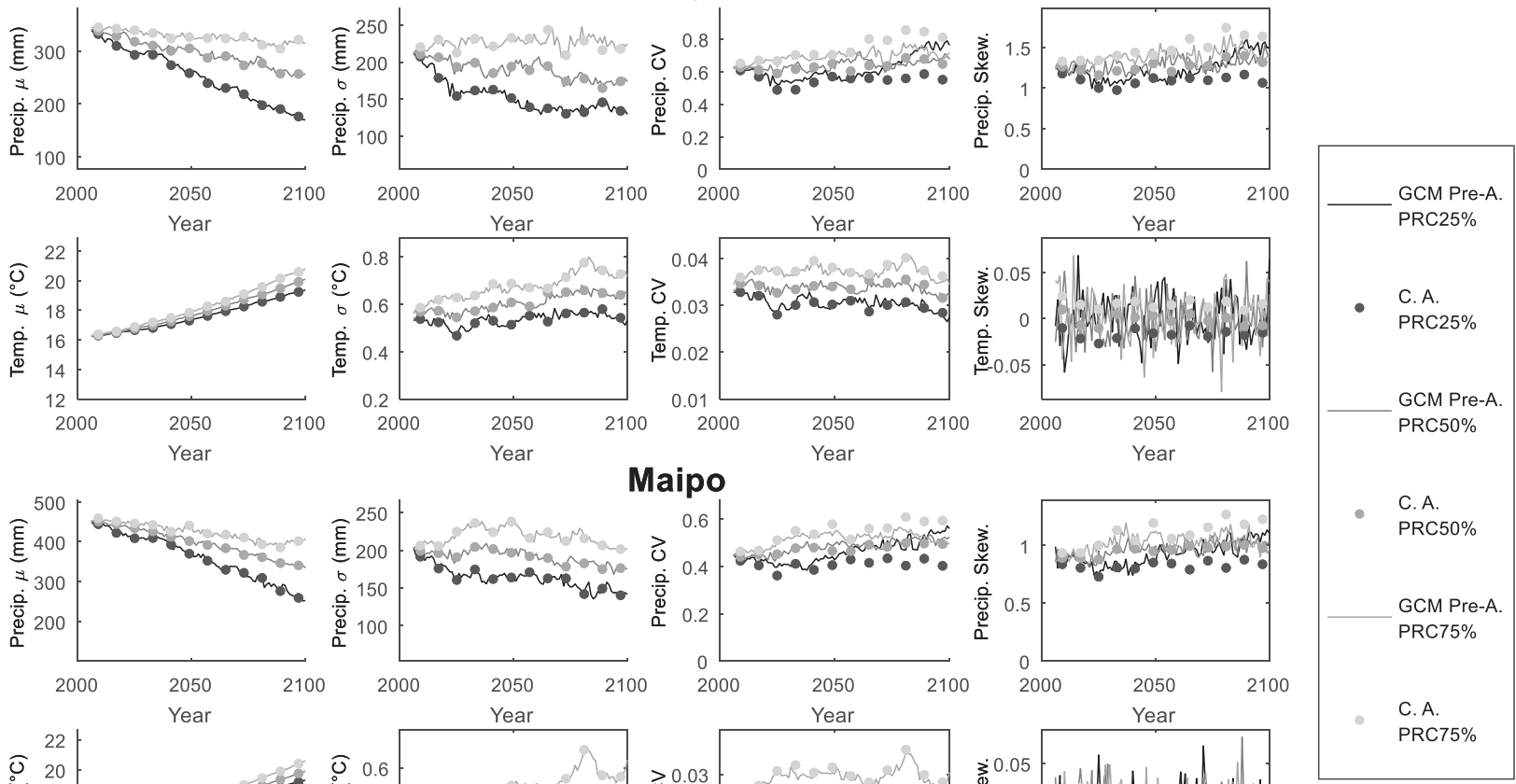

Maipo
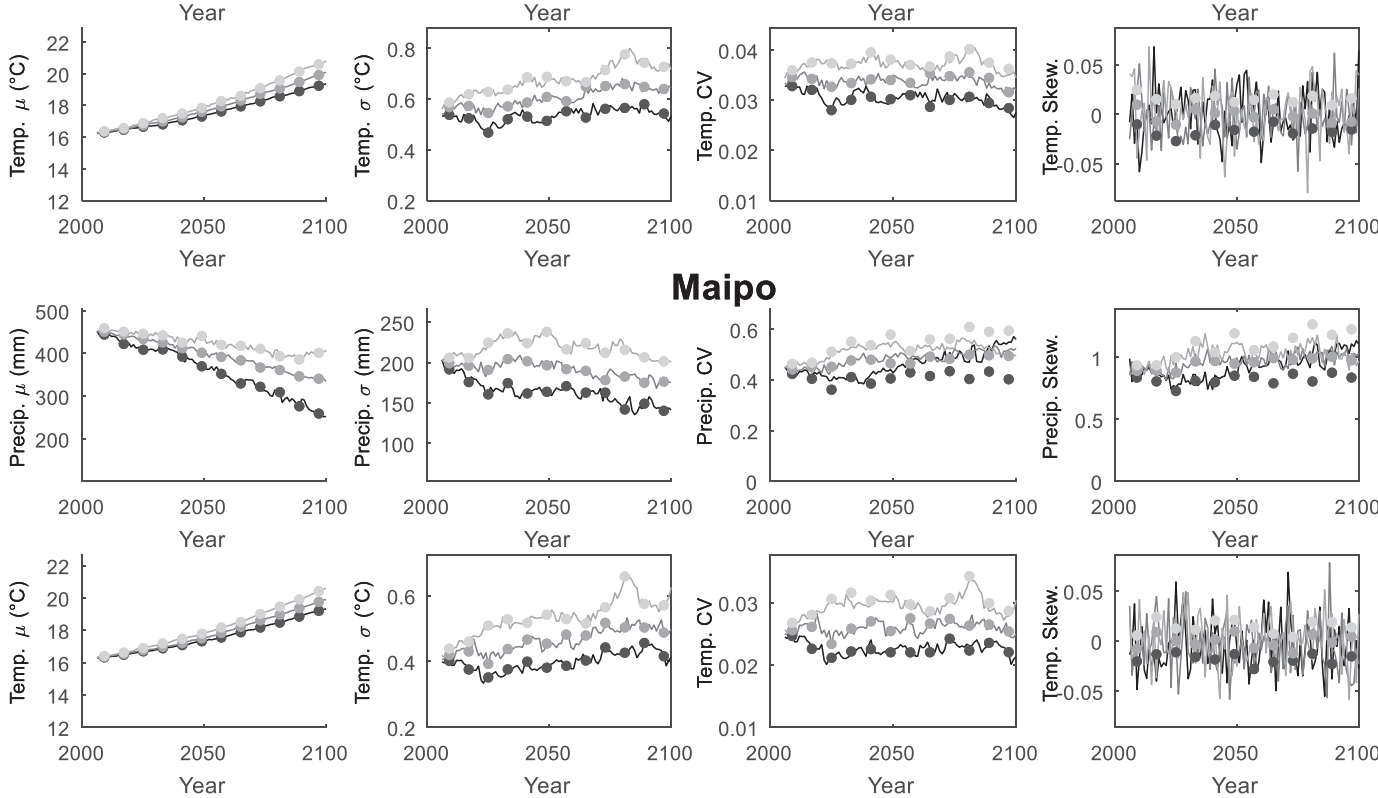

C. A.

Maule
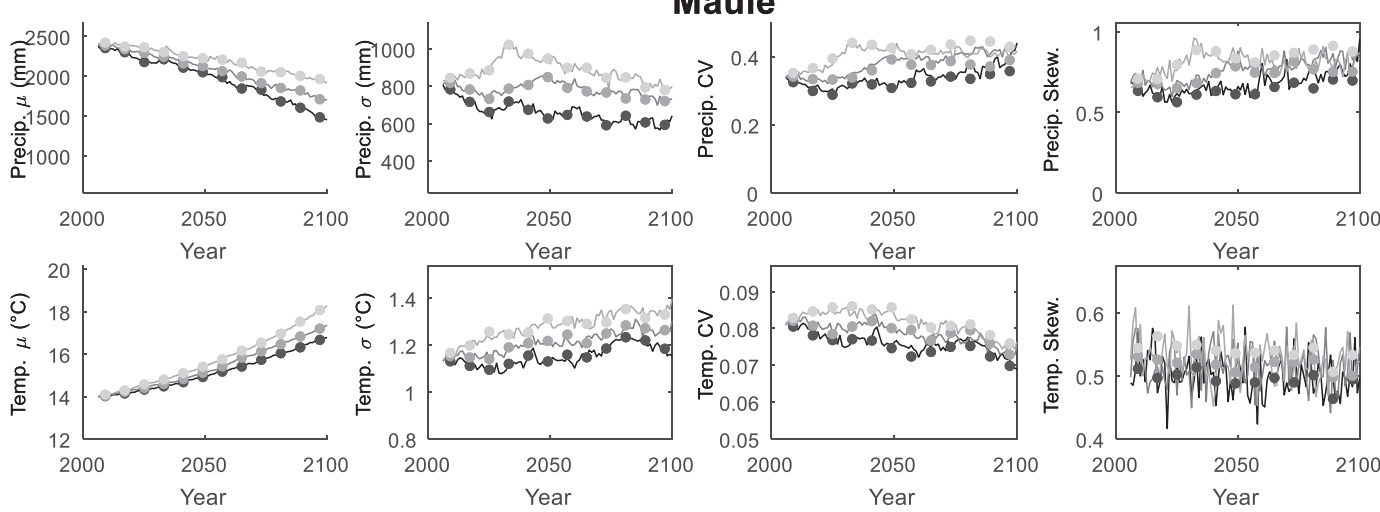

FIG. 4. Comparison of the 25th, 50th, and 75th GCM percentiles of the (first column) mean, (second column) standard deviation, (third column) CV, and (fourth column) skewness obtained with the GCM preanalysis and the conventional analysis (C. A.) approaches. The analysis is performed for precipitation in the first, third, and fifth rows and temperature in the second, fourth, and sixth rows in the (top) Limarí, (middle) Maipo, and (bottom) Maule basins. The same percentiles for the mean and the standard deviation were used in the GCM preanalysis.

of the main statistical properties. We now test the ability of the method to reproduce future precipitation and the recurrence of different magnitudes and durations. We assess GCM preanalysis approach by comparing future consecutive number of years with precipitation under a threshold by year 2070 for the Limarí, Maipo, and Maule River basins against those estimated by the conventional analysis approach (Fig. 6). In particular, we count the number of time windows of 3,6 , and 10 consecutive years with precipitation under a certain value. In the case of conventional analysis, we counted the number of time windows in a $10000-y r$ realization of what is predicted for the year 2070 by each of the 45 GCM projections. The average number of time windows from the 45 series is then reported in Fig. 6 and compared against the result from the GCM preanalysis case. In the latter, 

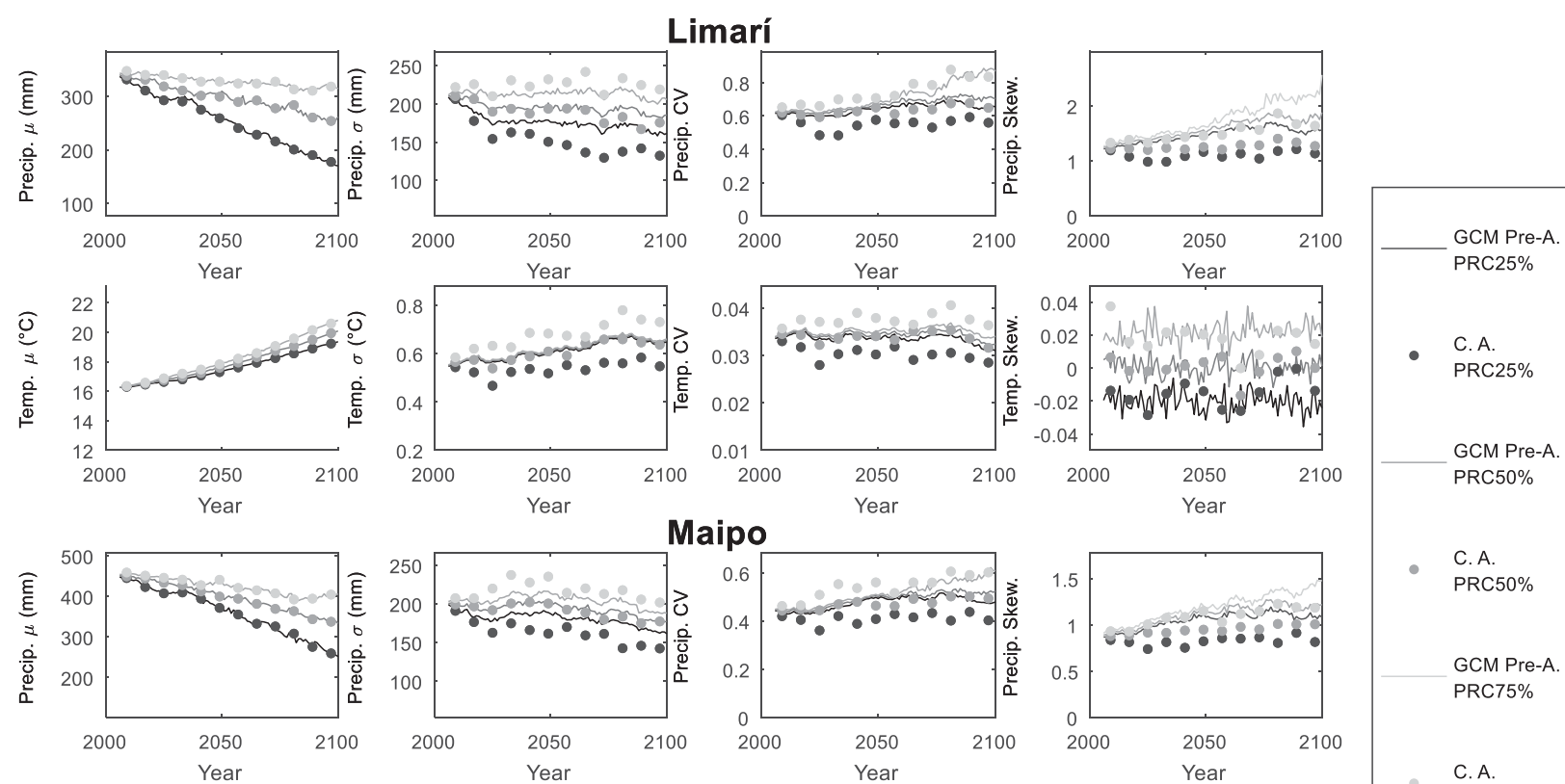

Maipo
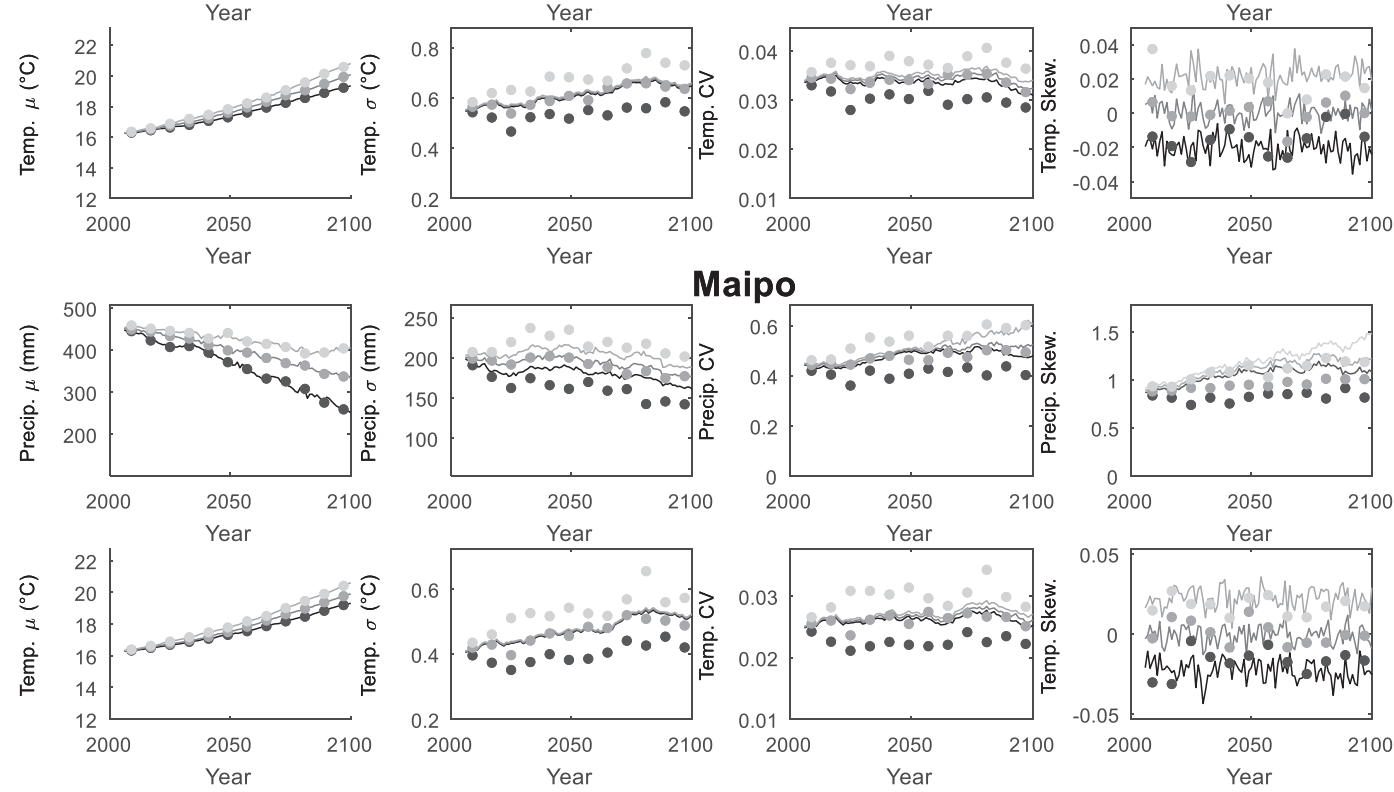

- C. A.
PRC25\%
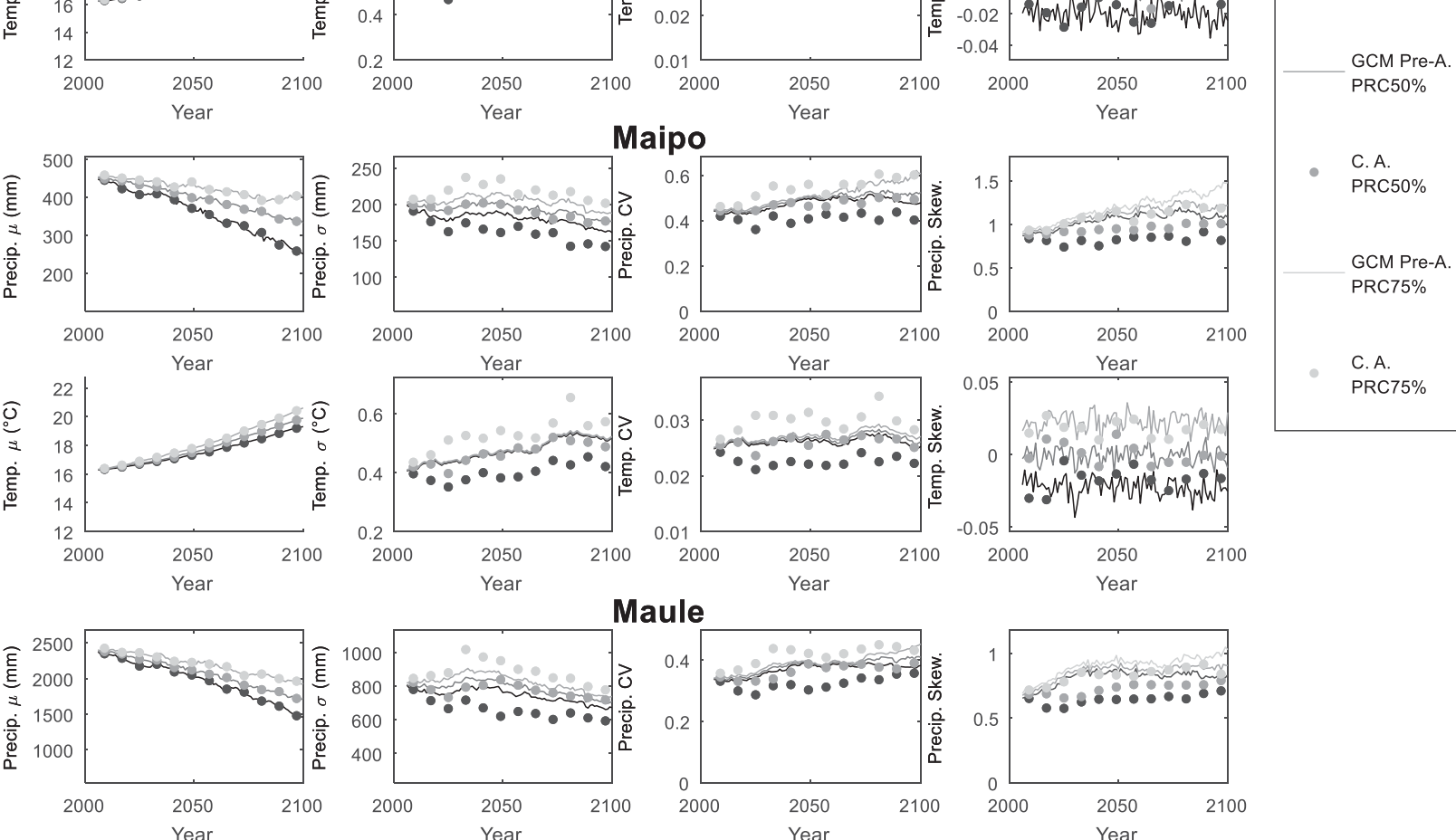

Maule
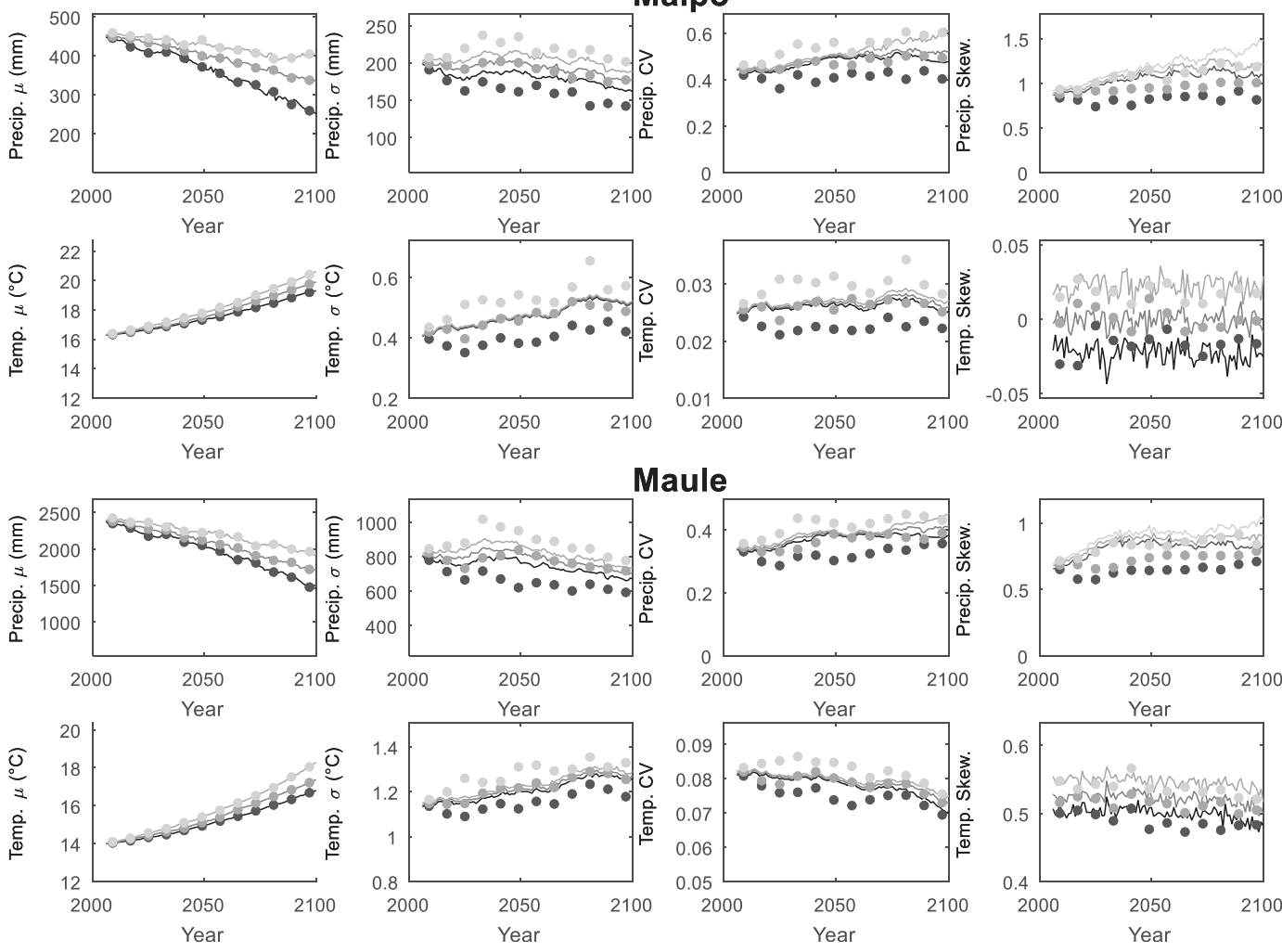

C. A.

PRC50\%

GCM Pre-A. PRC75\%

C. A. PRC75\%
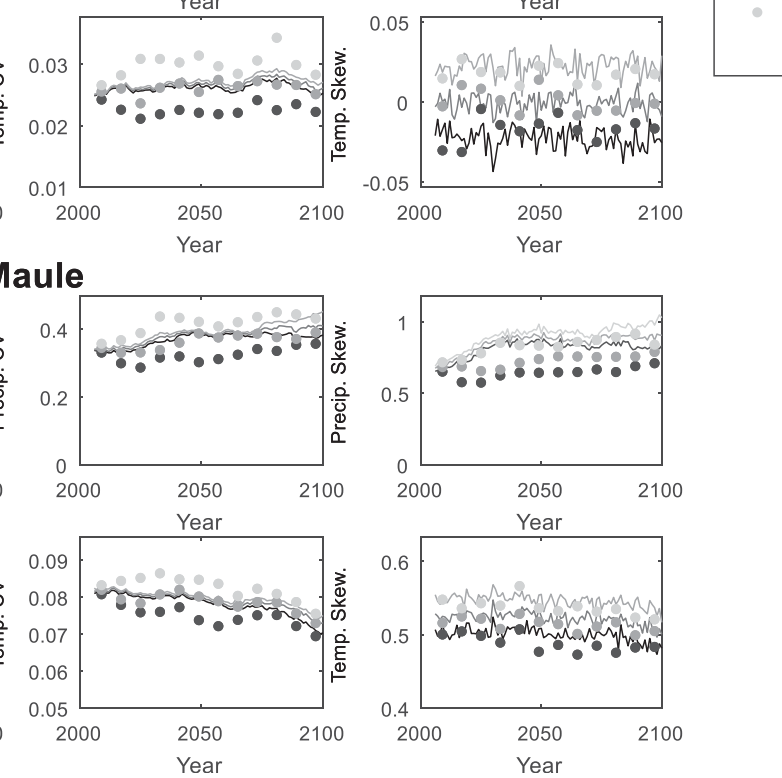

FIG. 5. As in Fig. 4, but randomly correlated percentiles for the mean and the standard deviation were used in the GCM preanalysis.

the number of time windows was also obtained after averaging the number of time windows identified from each of the 10000 simulations of year 2070 using 45 and 5 equally spaced trend percentiles of $\mu$. The 45 trend percentiles were used to have the same number of trends and GCM projections, while using 5 trend percentiles implies a simplified version adopted to better understand the capacity of the proposed method to deal with uncertainty using a reduced number of trend percentiles. Note than in this case the percentiles of the $\sigma$ trend were randomly selected considering the correlation with the $\mu$ trend.
The difference (in percentage) between the results from both GCM treatment approaches when using the 45 trend percentiles decreases with the number of time windows being identified. The maximum percentage error decreases from $-100 \%$ (Fig. 6e) to $12.2 \%$ (Fig. 6i) up to $3.3 \%$ (Fig. 6a) as the average number of detected time windows goes from $\sim 1$ to 35 or more, up to 200 or more, respectively. Overall the number of time windows for the three basins is similar regardless of the length of the time window adopted, showing the effectiveness of the GCM preanalysis method to deal in a simple manner with a wide range of GCM climate projections. Interestingly, the 

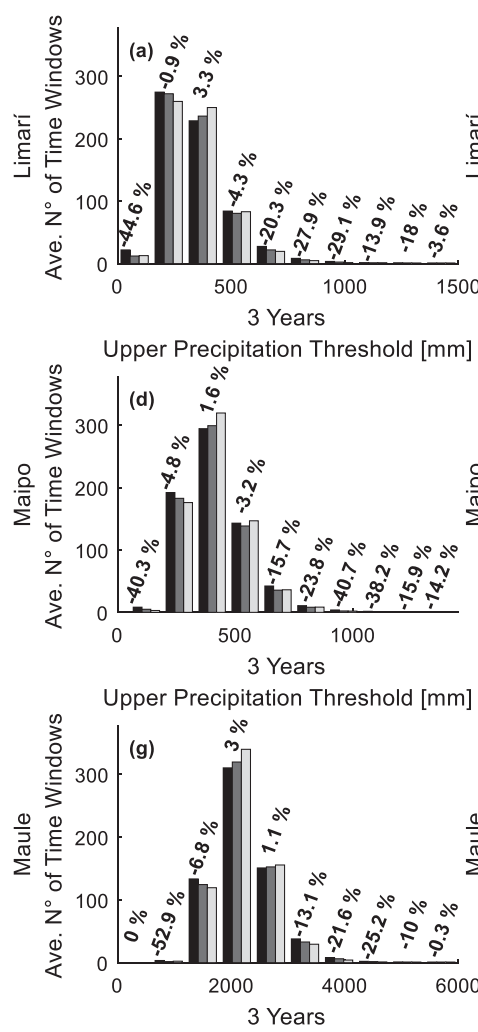

Upper Precipitation Threshold [mm]
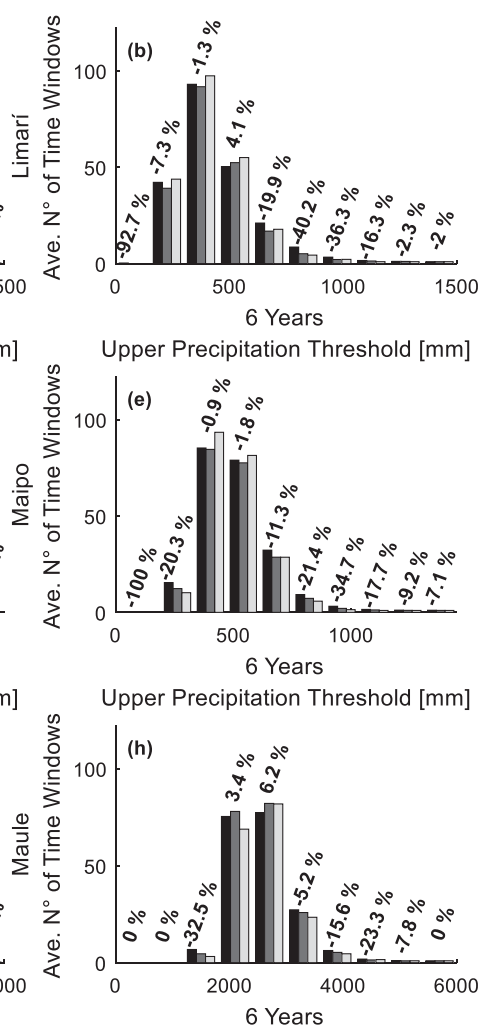

Upper Precipitation Threshold [mm]
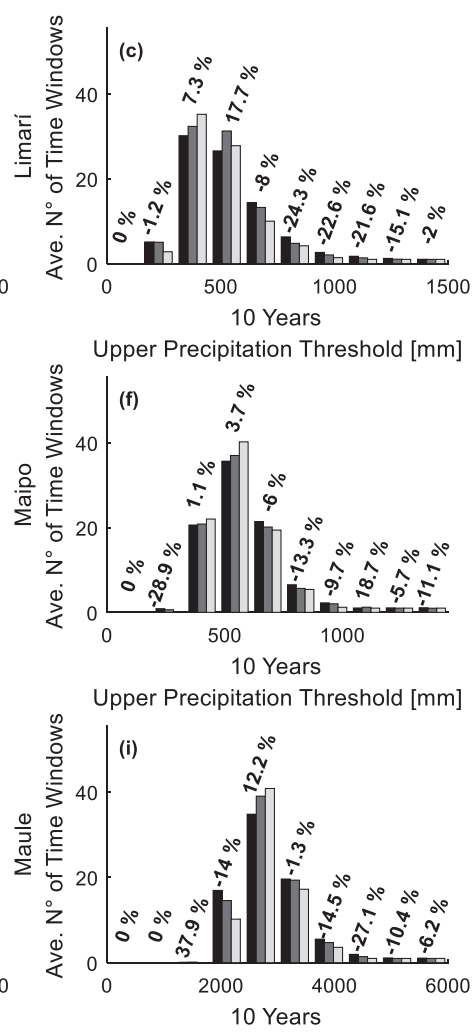

Upper Precipitation Threshold [mm]

FIG. 6. Average number of series with exactly 3, 6, and 10 consecutive years with precipitation under a certain value from 10000 years of simulation with the $45 \mathrm{GCMs}$ (conventional analysis), 45 percentiles, and 5 percentiles for the climate series generator (GCM preanalysis). The comparison is performed for the year 2070 for the three river basins. The difference in percentage between the 45 percentiles of GCM preanalysis and conventional analysis is presented above the bars.

GCM preanalysis with only 5 trend percentiles is remarkably similar to that using 45 trend percentiles, with maximum percentage errors a bit larger than the ones previously mentioned.

Future water scarcity is a big concern in Mediterranean regions, especially in those Chilean locations where a drier and warmer climate is expected (Vicuña et al. 2011; Meza et al. 2012; Vicuña et al. 2012; Demaria et al. 2013). Future precipitation conditions on Limarí, Maipo, and Maule basins can be analyzed by estimating the probability of 3-6-yr and 10-yr precipitation falling below a certain threshold magnitude, regardless of what happens in the years before or after. For this purpose, using conventional analysis approach, we simulated 10000 -yr realizations of the future climate projections of years 2050 (midterm) and 2090 (long term). We used each of the 45 future GCM projections and counted the number of times in which the abovementioned condition was identified. This number, divided by the total number of years of simulation, is what was used to estimate the probability. For the preanalysis approach, we only used five equally spaced trend percentiles of $\mu$. Again, the total count divided by the number of years in the simulation corresponded to the probability. Later on, we explain the rationale behind the selection of five percentiles.

The abovementioned probabilities for the three basins and the two future years (2050 and 2090) are shown in Fig. 7. For example, for the year 2050, there is a $36 \%$ probability that the following 3 years will have less precipitation than the average of $341.5 \mathrm{~mm}$ in the Limari basin (Fig. 7a). Note that these probabilities combine the effect of both climate uncertainty (i.e., that related to the standard deviation of the stationary precipitation) and uncertainty related to the discrepancy among the GCMs under RCP8.5. To complement results in Fig. 7, Table 2 lists the probabilities of having 3, 6, and 10 consecutive years with less precipitation than the historical average reported in Table 1 for the study basins. Table 2 also has the probabilities of having 3, 6, and 10 consecutive years under the average for the stationary historical scenario. For the stationary scenario, the current probability of having three consecutive dry years 

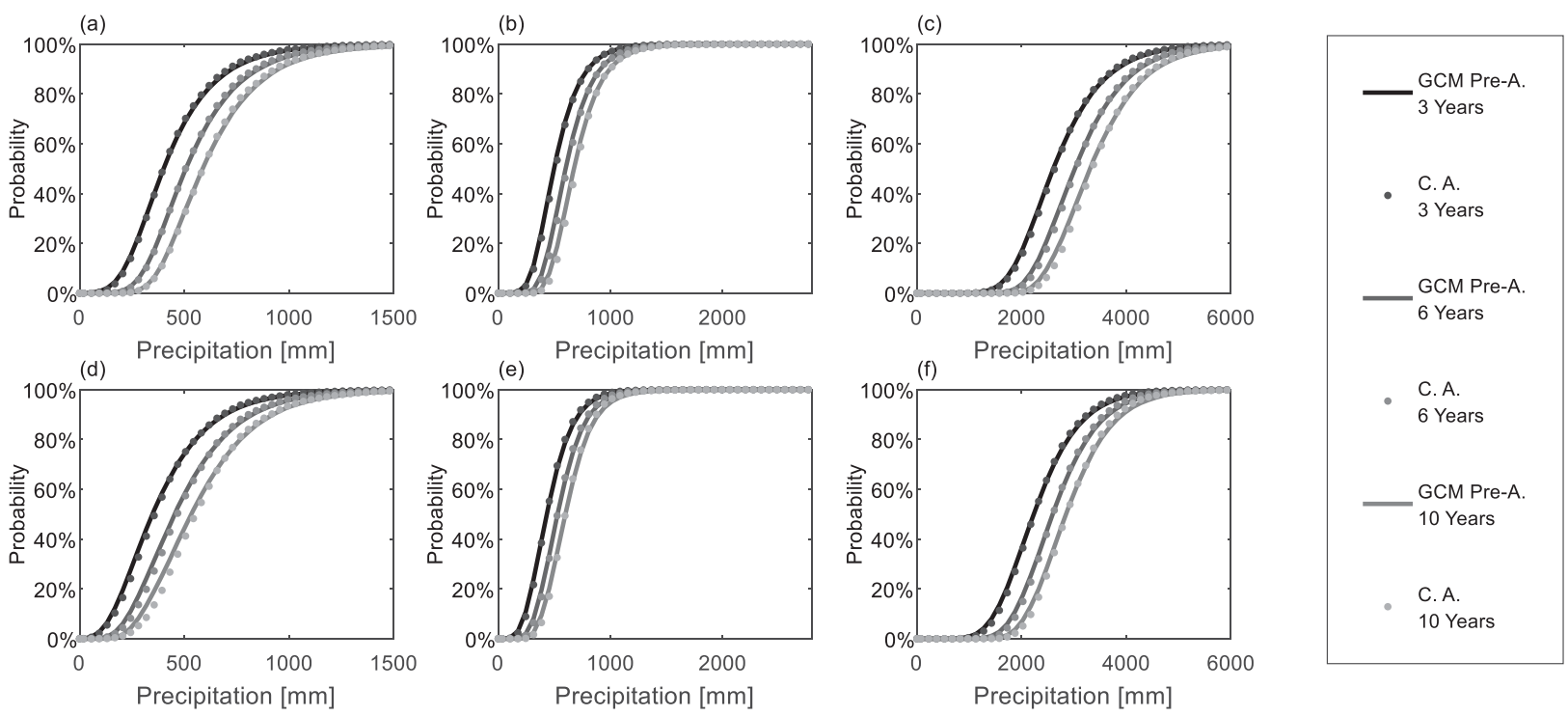

(h)
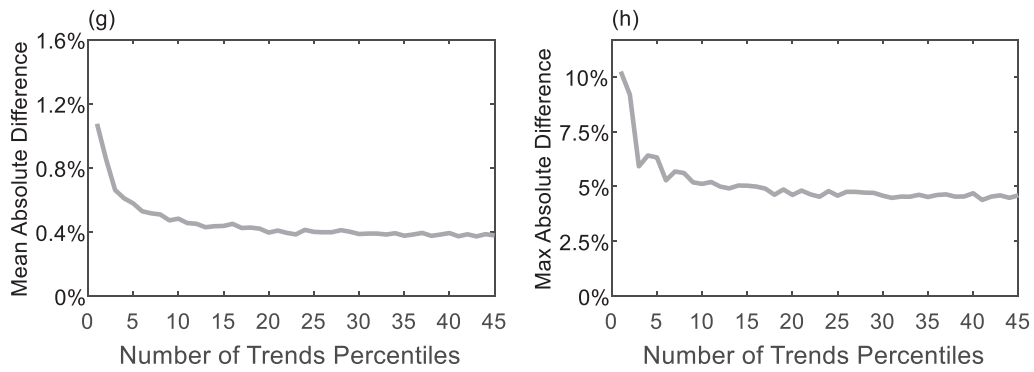

FIG. 7. Probability of having 3,6, and 10 consecutive years with precipitation lower than a certain value for the (a),(d) Limarí, (b),(e) Maipo, and (c),(f) Maule basins, using GCM preanalysis and conventional analysis (C. A.). The analysis is performed for year (top) 2050 and (middle) 2090. (bottom) The overall (g) mean absolute and (h) maximum absolute difference of the comparison of both approaches for several numbers of trend percentiles of the GCM preanalysis.

in the Limarí is $23 \%$, which is similar that of Maipo $(24 \%)$ and slightly higher than the one of Maule (20\%). By year 2050 these probabilities increase in the Maipo to $40 \%$, in Maule to 38\%, and in Limarí to 36\%. By 2090 the probability of having 3,6 , and 10 consecutive dry years will be much higher for Maule basin (i.e., $59 \%$, $38 \%$, and $24 \%$, respectively) as compared to the probabilities expected for the Maipo basin $(54 \%, 33 \%$, and $20 \%$ ) and the Limarí basin (49\%, 29\%, and 17\%).

Figures $7 \mathrm{~g}$ and $7 \mathrm{~h}$ show the mean and maximum absolute difference of the probability of consecutive years below different precipitation thresholds between conventional analysis and GCM preanalysis for different numbers of equally spaced mean trend percentiles. Note that plots consider all the basins, two future years of evaluation, and several realizations for smoothing the curve. With five or more trends used for the GCM preanalysis, differences with respect to the results from conventional analysis are significantly reduced. For example, by using only one trend in the GCM preanalysis, the differences with conventional analysis are more than double the one obtained when using five or more trends. Figures $7 \mathrm{~g}$ and $7 \mathrm{~h}$ support the use of the GCM preanalysis approach for two reasons. First, using 5-10 trends significantly reduces the error compared to using a GCM single trend. Second, the difference between the GCM preanalysis and conventional analysis is fairly small. Note that a GCM single trend is equivalent to the widely used single GCM ensemble (Kim and Kaluarachchi 2009; Greene et al. 2012).

To evaluate the severity of the future reductions in precipitation over the study basins, we defined the changes in annual precipitation $\left(\mathrm{CAP}_{j, i}\right)$ index, which is similar to the well-known standardized precipitation index (SPI; McKee et al. 1993; Bhuiyan et al. 2006; Burke and Brown 2008; Khan et al. 2008):

$$
\mathrm{CAP}_{j, i}=\frac{\mathrm{PP}_{j, i}-\mu_{i}}{\sigma_{i}}
$$

The $\mathrm{CAP}_{j, i}$ index is computed for each year $j$ using the moving average of $i$ years. It corresponds to a 
TABLE 2. Probability of observing 3, 6, and 10 consecutive years with precipitation lower than the historical mean for the Limarí, Maipo, and Maule basins. Three cases are considered: a stationary scenario assuming historical values and a midcentury (2050) and end of century (2090) year.

\begin{tabular}{|c|c|c|c|c|c|c|c|c|c|c|}
\hline \multirow[b]{2}{*}{ Basin } & \multirow[b]{2}{*}{ Station } & \multicolumn{3}{|c|}{3 consecutive years } & \multicolumn{3}{|c|}{6 consecutive years } & \multicolumn{3}{|c|}{10 consecutive years } \\
\hline & & $\begin{array}{l}\text { Stationary } \\
\text { scenario }\end{array}$ & $\begin{array}{l}\text { Year } \\
2050\end{array}$ & $\begin{array}{l}\text { Year } \\
2090\end{array}$ & $\begin{array}{l}\text { Stationary } \\
\text { scenario }\end{array}$ & $\begin{array}{l}\text { Year } \\
2050\end{array}$ & $\begin{array}{l}\text { Year } \\
2090\end{array}$ & $\begin{array}{l}\text { Stationary } \\
\text { scenario }\end{array}$ & $\begin{array}{l}\text { Year } \\
2050\end{array}$ & $\begin{array}{l}\text { Year } \\
2090\end{array}$ \\
\hline Limarí & Las Ramadas & $23 \%$ & $36 \%$ & $49 \%$ & $6 \%$ & $15 \%$ & $29 \%$ & $1 \%$ & $5 \%$ & $17 \%$ \\
\hline Maipo & Cerro Calán & $24 \%$ & $40 \%$ & $54 \%$ & $6 \%$ & $18 \%$ & $33 \%$ & $1 \%$ & $8 \%$ & $20 \%$ \\
\hline Maule & Armerillo & $20 \%$ & $38 \%$ & $59 \%$ & $4 \%$ & $17 \%$ & $38 \%$ & $1 \%$ & $7 \%$ & $24 \%$ \\
\hline
\end{tabular}

standardized moving-average annual precipitation obtained by subtracting the mean of the annual historical precipitation moving average $\mu_{i}$ from the $i$ years moving average annual precipitation $\left(\mathrm{PP}_{j, i}\right)$ and dividing by the standard deviation of the annual historical precipitation moving average $\sigma_{i}$.

Figure 8 shows the continuous temporal change of the probability of having values of the $\mathrm{CAP}_{j, i}$ index under $0,-0.5$, and -1 in the three basins, for two values of moving average window (i.e., $i=1$ and 4 years). Again, the results obtained from both the GCM preanalysis and conventional analysis are compared, although in this case the continuous change is evaluated. These probabilities also combine the effect of both the climate uncertainty and the uncertainty related to the discrepancy among the GCMs under RCP8.5. Only 5 equally spaced mean trend percentiles are used for GCM preanalysis, while conventional analysis uses the 45 future GCM projections (Figs. 8a-f). To assess the impact of the number of trend percentiles chosen for the preanalysis approach, we used different numbers of equally spaced mean trend percentiles to calculate the mean difference and maximum absolute difference of the probability of having $\mathrm{CAP}_{j, i}$ under $0,-0.5$, and -1 between the conventional analysis and the GCM preanalysis (Figs. 8g,h). Just as in Figs. $7 \mathrm{~g}$ and $7 \mathrm{~h}$, the difference between having GCM preanalysis and conventional analysis can be significantly reduced by considering five or more trends on the GCM preanalysis, instead of the single median GCM ensemble. Again, the GCM preanalysis allows reducing the error of not using a GCM group by using a multipletrend GCM ensemble, instead of a single median GCM ensemble.

The probability of $\mathrm{CAP}_{j, i=1}$ being under 0 for year 2020 and 2100 goes from $62 \%, 59 \%$, and $59 \%$ to $74 \%, 77 \%$, and $83 \%$ for the Limarí (Fig. 8a), Maipo (Fig. 8b), and Maule (Fig. 8c) basins, respectively. The probability of having $\mathrm{CAP}_{j, i=1}<-1$ for years 2020 and 2100 worsens for Limarí (i.e., going from $14 \%$ to $29 \%$, Fig. 8 a), Maipo (i.e., going from $16 \%$ to $36 \%$, Fig. 8 b), and Maule (i.e., going from $18 \%$ to $49 \%$ Fig. 8 c) river basins. The Maule is the most affected basin, because the probability of having more negative values of $\mathrm{CAP}_{j, i=1}$ increases the most. The probability of $\mathrm{CAP}_{j, i=4}$ being under 0 for year 2020 and 2100 also worsens significantly for the Limarí (i.e., from $61 \%$ to $80 \%$, Fig. 8 d), Maipo (i.e., from $60 \%$ to $85 \%$, Fig. $8 \mathrm{e}$ ), and Maule (i.e., from $58 \%$ to $93 \%$, Fig. 8f) basins. Again, the probability of $\mathrm{CAP}_{j, i=4}$ being under -1 for year 2020 and 2100 worsens for the Limarí (i.e., going from $35 \%$ to $63 \%$, Fig. 8d), Maipo (i.e., going from $31 \%$ to $67 \%$, Fig. 8 e), and Maule (i.e., going from $23 \%$ to $76 \%$, Fig. 8f) basins. Once more, the most affected basin is the Maule basin, showing a steeper slope of $\mathrm{CAP}_{j, i}$, which indicates grater changes in its precipitation through the century.

\section{Conclusions}

In this paper we propose an ensemble technique for the unbiased mapping of GCM changes in precipitation and temperature to local stations, based on both the statistical preanalysis of the GCMs and the inclusion of natural climate variability. The method was implemented in three Mediterranean basins in Chile (Limarí, Maipo, and Maule) and evaluated against a conventional analysis method in which each GCM is individually used to build future climatic scenarios from which percentiles are computed. This evaluation included the assessment of the ability to reproduce statistical moments and to estimate the length, severity, and probability of occurrence of precipitation under different thresholds. Moreover, the preanalysis approach was also compared against commonly used downscaling and/or bias correction approaches (quantile mapping bias correction, a GCM subset selection, and delta change). The following conclusions are emphasized:

- The best approach to reproduce both local climate and incorporate the changes from the raw GCM projections is the conventional analysis, followed by the 

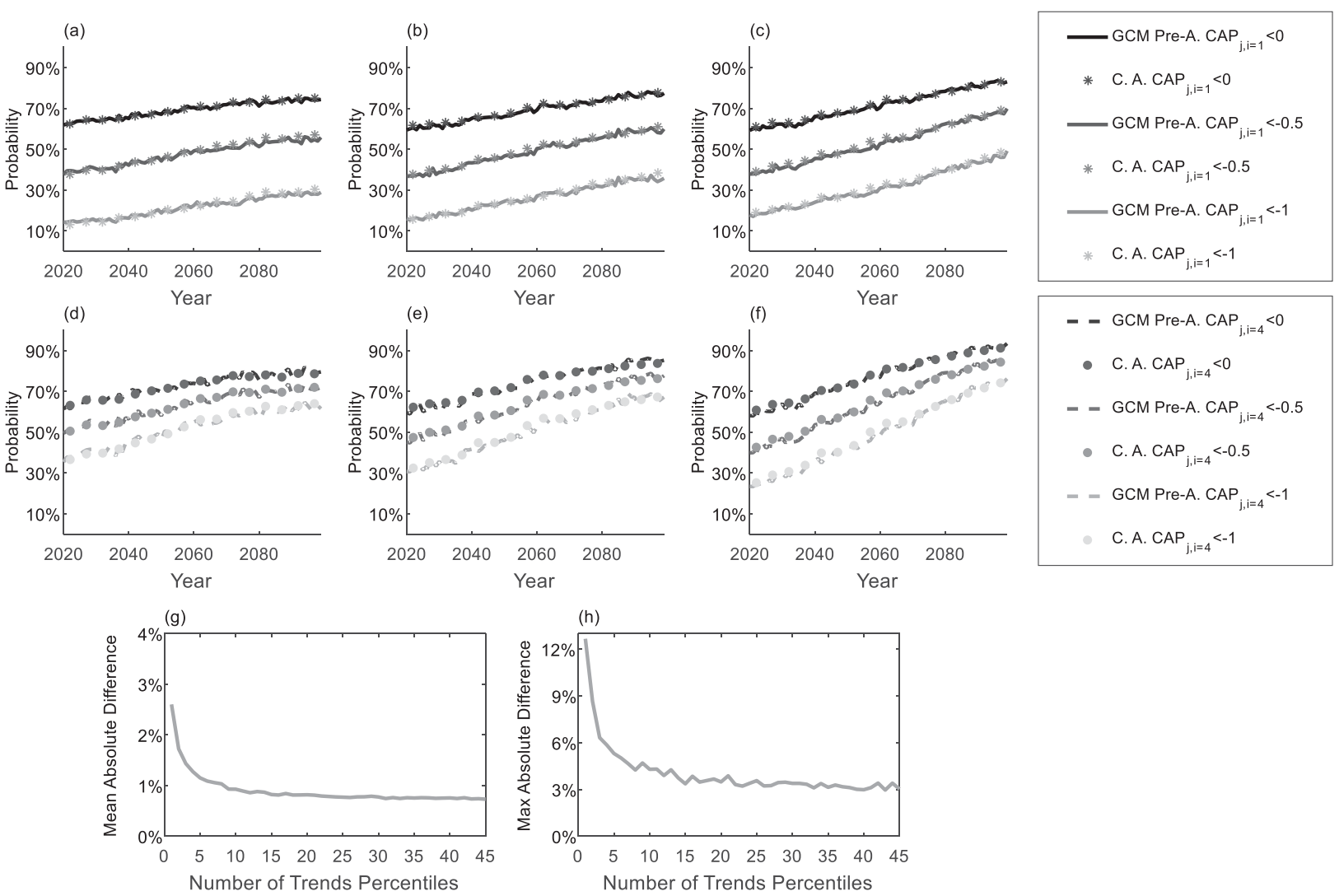

FIG. 8. Probability of having (top) $\mathrm{CAP}_{j, i=1}$ and (middle) $\mathrm{CAP}_{j, i=4}$ under $0,-0.5$, and -1 for the (a),(d) Limarí, (b),(e) Maipo, and (c),(f) Maule River basins, using GCM preanalysis and conventional analysis (C. A.). (bottom) The overall (g) mean absolute and (h) maximum absolute difference of the comparison of both approaches for several numbers of trend percentiles of the GCM preanalysis.

GCM preanalysis. Both methods outperform other commonly used downscaling and/or bias correction approaches.

- Results obtained using GCM preanalysis and conventional analysis are very similar. On average there is less than a $0.4 \%$ difference between the probabilities of future years below different precipitation thresholds estimated with both methods.

- Using 5-10 trend percentiles obtained from the GCM preanalysis is clearly better than using the single trend of the median GCM ensemble, as in the last case the uncertainty or discrepancy among the group of GCMs is not formally considered. The GCM preanalysis has the advantage of building GCM ensembles that incorporate not only the mean or median, but also the entire range of climate projections of a group of GCMs.

- The GCM preanalysis is able to simulate accurately the percentiles of the mean and the standard deviation of the temperature and precipitation of a group of
GCMs. The percentiles of the skewness and coefficient of variation are less well represented.

Despite its good performance, the GCM preanalysis is an ensemble technique that does not allow the preservation of the physical internal consistency of an individual GCM. If such consistency were crucial, the conventional analysis is recommended. Thus, the method here proposed must be understood as an ensemble-type approach that successfully preserves the local climate while incorporating the GCMs' statistical attributes.

Considering that the GCM percentiles can be chosen at the beginning of the GCM preanalysis, the proposed method becomes an attractive alternative to assess climate change uncertainty and perform impact studies. Furthermore, the application of the approach to other river basins is quite auspicious due to its good performance in challenging basins with high annual precipitation variability. As the method incorporates both the local climate and the GCM changes, it allows the identification of the most vulnerable basins to climate change in a certain region or 
TABLE A1. Meteorological stations in the Limarí basin measuring precipitation $P$ and temperature $T$.

\begin{tabular}{lcccc}
\hline \multicolumn{1}{c}{ Station } & Variable & Elevation $(\mathrm{m})$ & Latitude & Longitude \\
\hline Pabellón & $P$ & 1920 & $30^{\circ} 24^{\prime} 12^{\prime \prime} \mathrm{S}$ & $70^{\circ} 33^{\prime} 08^{\prime \prime} \mathrm{W}$ \\
Las Ramadas & $P, T$ & 1380 & $31^{\circ} 01^{\prime} 11^{\prime \prime} \mathrm{S}$ & $70^{\circ} 35^{\prime} 11^{\prime \prime} \mathrm{W}$ \\
Tascadero & $P$ & 1230 & $31^{\circ} 00^{\prime} 58^{\prime \prime} \mathrm{S}$ & $70^{\circ} 40^{\prime} 28^{\prime \prime} \mathrm{W}$ \\
Cogotí 18 & $P$ & 840 & $31^{\circ} 05^{\prime} 12^{\prime \prime} \mathrm{S}$ & $70^{\circ} 57^{\prime} 08^{\prime \prime} \mathrm{W}$ \\
Recoleta & $P$ & 350 & $30^{\circ} 30^{\prime} 36^{\prime \prime} \mathrm{S}$ & $71^{\circ} 06^{\prime} 07^{\prime \prime} \mathrm{W}$ \\
$\quad$ Embalse & & & & \\
Paloma & $P, T$ & 320 & $30^{\circ} 41^{\prime} 48^{\prime \prime} \mathrm{S}$ & $71^{\circ} 02^{\prime} 18^{\prime \prime} \mathrm{W}$ \\
$\quad$ Embalse & & & & \\
El Tomé & $P$ & 420 & $30^{\circ} 49^{\prime} 12^{\prime \prime} \mathrm{S}$ & $70^{\circ} 58^{\prime} 08^{\prime \prime} \mathrm{W}$ \\
Punitaqui & $P$ & 280 & $30^{\circ} 49^{\prime} 35^{\prime \prime} \mathrm{S}$ & $71^{\circ} 15^{\prime} 37^{\prime \prime} \mathrm{W}$ \\
Ovalle DGA & $P$ & 220 & $30^{\circ} 36^{\prime} 12^{\prime \prime} \mathrm{S}$ & $71^{\circ} 12^{\prime} 08^{\prime \prime} \mathrm{W}$ \\
\hline
\end{tabular}

country, and the eventual prioritization of investments. From the three basins here studied, the Maule basin is the one for which we identified the highest probability of being drier in the future. Nevertheless, one should also consider the magnitude of changes in precipitation and the socioeconomic and environmental impacts of these drier conditions, before making any decision or taking action.

Acknowledgments. This research is the result of research projects Fondecyt Grant 1171133 and International Development Research Center (IDRC) Grant 107081-001. We also thank the support from Grants CONICYT/FONDAP/15110017 and 15110020. Scholarships from CONICYT (21160861), Sociedad de Canal del Maipo, and Vice-rectoría de Investigación at Universidad Católica de Chile are acknowledged by Cristián Chadwick. We want to thank both the World Climate Research Programme's Working Group on Coupled Modelling, which is responsible for CMIP, and the climate modeling groups (appendix B) for making available their model outputs. We finally thank the referees for their constructive suggestions and Dr. Pilar Barria for a final revision of the manuscript. Meteorological data for this study are publicly available from the Dirección General de Aguas, Chile (http://snia. dga.cl/BNAConsultas/reportes).

\section{APPENDIX A}

\section{Correlation among Meteorological Data}

To preserve the spatial correlation and the correlation between temperature and precipitation, we use the correlation matrix of the historical annual data to generate correlated uniform random numbers $u[0,1]$. Using $y=F_{Y}^{-1}(u, \theta)$ we obtain random values of temperature and precipitation in each station that preserve the observed correlation. Random uniform numbers are produced using a vector autoregressive model VAR $(0)$, although a VAR(1) model can also be used in case temporal correlation were to be considered. Indeed, a VAR(1) model was tested in the application here reported, but results are not presented as autocorrelation is not statistically significant for annual observed data. In the implementation of the VAR(0) model, correlated random numbers following a standardized normal distribution are first generated (step 1) and subsequently transformed into uniformly distributed correlated values, using the correlation matrix for space transformation described by Hotelling and Pabst (1936) (step 2). In particular, in step 1 we apply the Cholesky factorization of the correlation matrix in the normal space to transform uncorrelated to correlated normally distributed random values. In step 2 the inverse normal distribution transforms these numbers into uniform correlated values.

To verify the method, we tested it in replicating stationary annual climate of nine precipitation stations and two temperature stations located in the Limarí basin (Table A1). We generated 10000 years of stationary annual precipitation and temperature correlated data from the stations listed in Table A1, to obtain the results presented in Table A2. As shown

TABLE A2. Comparison between observed (Obs) and simulated annual statistics using the annual climate generator (Gen) for precipitation $P$ and temperature $T$ gauges in the Limarí basin. Annual correlation (A. corr.) is computed between annual precipitation in Las Ramadas gauge and the rest of the rain gauges and temperature measurements in the basin.

\begin{tabular}{|c|c|c|c|c|c|c|c|c|c|c|c|}
\hline & Pabellon & $\begin{array}{c}\text { Las } \\
\text { Ramadas }\end{array}$ & Tascadero & Cogotí 18 & $\begin{array}{l}\text { Recoleta } \\
\text { Embalse }\end{array}$ & $\begin{array}{l}\text { Paloma } \\
\text { Embalse }\end{array}$ & $\begin{array}{c}\text { El } \\
\text { Tomé }\end{array}$ & Punitaqui & $\begin{array}{l}\text { Ovalle } \\
\text { DGA }\end{array}$ & $\begin{array}{c}\text { Las } \\
\text { Ramadas }\end{array}$ & $\begin{array}{l}\text { Paloma } \\
\text { Embalse }\end{array}$ \\
\hline Variable & $P(\mathrm{~mm})$ & $P(\mathrm{~mm})$ & $P(\mathrm{~mm})$ & $P(\mathrm{~mm})$ & $P(\mathrm{~mm})$ & $P(\mathrm{~mm})$ & $P(\mathrm{~mm})$ & $P(\mathrm{~mm})$ & $P(\mathrm{~mm})$ & $T\left({ }^{\circ} \mathrm{C}\right)$ & $T\left({ }^{\circ} \mathrm{C}\right)$ \\
\hline Mean (Gen) & 162.5 & 340.9 & 299.8 & 192.7 & 110.4 & 139.3 & 173.3 & 170.5 & 110.4 & 16.25 & 17.22 \\
\hline Mean (Obs) & 163.0 & 341.5 & 300.4 & 192.6 & 110.1 & 139.1 & 173.2 & 170.3 & 109.8 & 16.25 & 17.22 \\
\hline Std dev (Gen) & 103.5 & 208.9 & 202.2 & 132.9 & 81.3 & 100.9 & 124.0 & 134.8 & 78.7 & 0.55 & 0.34 \\
\hline Std dev (Obs) & 104.4 & 209.8 & 203.5 & 133.0 & 80.9 & 100.7 & 123.9 & 134.6 & 78.0 & 0.54 & 0.34 \\
\hline A. Corr. (Gen) & 0.94 & 1.00 & 0.98 & 0.92 & 0.89 & 0.92 & 0.94 & 0.92 & 0.88 & -0.42 & 0.32 \\
\hline A. Corr. (Obs) & 0.94 & 1.00 & 0.98 & 0.93 & 0.89 & 0.92 & 0.94 & 0.92 & 0.88 & -0.43 & 0.33 \\
\hline
\end{tabular}


in Table A2, the proposed method successfully replicates the mean, standard deviation, and correlation among precipitation and temperature in the different stations.

\section{APPENDIX B}

\section{GCMs Used in This Study}

Table B1 contains GCMs used in this study.

TABLE B1. GCMs used in this study.

\begin{tabular}{|c|c|c|}
\hline Number & GCM name & GCM realization \\
\hline 1 & ACCESS1.0 & r1i1p1 \\
\hline 2 & BCC_CSM1.1 & r1i1p1 \\
\hline 3 & CanESM2 & r1i1p1 \\
\hline 4 & CanESM2 & r2i1p1 \\
\hline 5 & CanESM2 & r3i1p1 \\
\hline 6 & CanESM2 & r4i1p1 \\
\hline 7 & CanESM2 & r5ilp1 \\
\hline 8 & CCSM4 & r1i1p1 \\
\hline 9 & CCSM4 & r2i1p1 \\
\hline 10 & CCSM4 & r3i1p1 \\
\hline 11 & CCSM4 & r4i1p1 \\
\hline 12 & CCSM4 & r5ilp1 \\
\hline 13 & CNRM-CM5 & r10i1p1 \\
\hline 14 & CNRM-CM5 & r1i1p1 \\
\hline 15 & CNRM-CM5 & r2i1p1 \\
\hline 16 & CNRM-CM5 & r4i1p1 \\
\hline 17 & CNRM-CM5 & r6ilp1 \\
\hline 18 & CSIRO Mk3.6.0 & r10i1p1 \\
\hline 19 & CSIRO Mk3.6.0 & r1i1p1 \\
\hline 20 & CSIRO Mk3.6.0 & r2i1p1 \\
\hline 21 & CSIRO Mk3.6.0 & r3i1p1 \\
\hline 22 & CSIRO Mk3.6.0 & r4i1p1 \\
\hline 23 & CSIRO Mk3.6.0 & r5ilp1 \\
\hline 24 & CSIRO Mk3.6.0 & r6i1p1 \\
\hline 25 & CSIRO Mk3.6.0 & r7i1p1 \\
\hline 26 & CSIRO Mk3.6.0 & r8i1p1 \\
\hline 27 & CSIRO Mk3.6.0 & r9i1p1 \\
\hline 28 & FGOALS-g2 & r1i1p1 \\
\hline 29 & GFDL CM3 & r1ilp1 \\
\hline 30 & GFDL-ESM2G & r1i1p1 \\
\hline 31 & GFDL-ESM2M & r1ilp1 \\
\hline 32 & GISS-E2-R & r1i1p1 \\
\hline 33 & INM-CM4.0 & r1i1p1 \\
\hline 34 & IPSL-CM5A-LR & r1ilp1 \\
\hline 35 & IPSL-CM5A-LR & r2i1p1 \\
\hline 36 & IPSL-CM5A-LR & r3i1p1 \\
\hline 37 & IPSL-CM5A-MR & r1i1p1 \\
\hline 38 & MIROC5 & r1i1p1 \\
\hline 39 & MIROC-ESM & r1i1p1 \\
\hline 40 & MIROC-ESM-CHEM & r1i1p1 \\
\hline 41 & MPI-ESM-LR & r1i1p1 \\
\hline 42 & MPI-ESM-LR & r2i1p1 \\
\hline 43 & MPI-ESM-LR & r3i1p1 \\
\hline 44 & MRI-CGCM3 & r1i1p1 \\
\hline 45 & NorESM1-M & r1i1p1 \\
\hline
\end{tabular}

\section{REFERENCES}

Adeloye, A. J., N. R. Nawaz, and M. Montaseri, 1999: Climate change water resources planning impacts incorporating reservoir surface net evaporation fluxes: A case study. Int. J. Water Resour. Dev., 15, 561-581, https://doi.org/10.1080/07900629948763.

Ahmadalipour, A., H. Moradkhani, and A. Rana, 2018: Accounting for downscaling and model uncertainty in fine-resolution seasonal climate projections over the Columbia River Basin. Climate Dyn., 50, 717-733, https://doi.org/10.1007/s00382-017-3639-4.

Ayyub, B. M., and R. H. McCuen, 2011: Probability, Statistics and Reliability for Engineers and Scientists. CRC Press, 639 pp.

Bhuiyan, C., R. P. Singh, and F. N. Kogan, 2006: Monitoring drought dynamics in the Aravalli region (India) using different indices based on ground and remote sensing data. Int. J. Appl. Earth Obs. Geoinf., 8, 289-302, https://doi.org/10.1016/j.jag.2006.03.002.

Boisier, J. P., and P. Aceituno, 2006: Changes in surface and upperair temperature along the arid coast of northern Chile. Preprints, Eighth Int. Conf. on Southern Hemisphere Meteorology and Oceanography, Foz do Iguaçu, Brazil, Amer. Meteor. Soc., 227-228.

Bown, F., and A. Rivera, 2007: Climate change and recent glacier behaviour in the Chilean Lake District. Global Planet. Change, 59, 79-86, https://doi.org/10.1016/j.gloplacha.2006.11.015.

Bras, R. L., R. Buchenan, and K. C. Curry, 1983: Real time adaptation closed loop control of reservoir with the High Aswan Dam as a case study. Water Resour. Res., 19, 33-52, https://doi.org/ 10.1029/WR019i001p00033.

Burke, E. J., and S. J. Brown, 2008: Evaluating uncertainties in the projection of future drought. J. Hydrometeor., 9, 292-299, https://doi.org/10.1175/2007JHM929.1.

Chen, J., F. P. Brissette, and R. Leconte, 2011: Uncertainty of downscaling methods in quantifying the impact of climate change on hydrology. J. Hydrol., 401, 190-202, https://doi.org/ 10.1016/j.jhydrol.2011.02.020.

Clark, M. P., and R. S. Pulwarty, 2003: Devising resilient responses to potential climate change impact. Ogmius Newsletter, No. 5, Center for Science and Technology Policy Research, Boulder, CO, 2-3, http://sciencepolicy.colorado.edu/ogmius/archives/ issue_5/index.html.

Datta, B., and S. J. Burges, 1984: Short-term, single, multiplepurpose reservoir operation: Importance of loss function and forecast errors. Water Resour. Res., 20,1167-1176, https://doi.org/ 10.1029/WR020i009p01167.

_ , and M. H. Houck, 1984: A stochastic optimization model for real-time operation of reservoirs using uncertain forecasts. Water Resour. Res., 20, 1039-1046, https://doi.org/10.1029/ WR020i008p01039.

Demaria, E. M. C., E. P. Maurer, B. Thrasher, S. Vicuña, and F. J. Meza, 2013: Climate change impacts on an alpine watershed in Chile: Do new model projections change the story? J. Hydrol., 502, 128-138, https://doi.org/10.1016/j.jhydrol.2013.08.027.

Diaz-Nieto, J., and R. L. Wilby, 2005: A comparison of statistical downscaling and climate change factor methods: Impacts on low flows in the River Thames, United Kingdom. Climatic Change, 69, 245-268, https://doi.org/10.1007/s10584-005-1157-6.

Downing, T. E., L. Ringius, M. Hulme, and D. Waughray, 1997: Adapting to climate change in Africa. Mitigation Adapt. Strategies Global Change, 2, 19-44, https://doi.org/10.1007/ BF02437055.

Fowler, H. J., C. G. Kilsby, P. E. O'Connell, and A. Burton, 2005: A weather-type conditioned multi-site stochastic rainfall model for the generation of scenarios of climatic variability and 
change. J. Hydrol., 308, 50-66, https://doi.org/10.1016/ j.jhydrol.2004.10.021.

Giese, B. S., S. C. Urizar, and N. S. Fučkar, 2002: Southern Hemisphere origins of the 1976 climate shift. Geophys. Res. Lett., 29, 1014, https://doi.org/10.1029/2001GL013268.

Giorgi, F., and X. Bi, 2009: Time of emergence (TOE) of GHGforced precipitation change hot-spots. Geophys. Res. Lett., 36, L06709, https://doi.org/10.1029/2009GL037593.

Greene, A. M., M. Hellmuth, and T. Lumsden, 2012: Stochastic decadal climate simulations for the Berg and Breede Water Management Areas, Western Cape province, South Africa. Water Resour. Res., 48, W06504, https://doi.org/10.1029/2011WR011152.

Hagemann, S., C. Chen, J. O. Haerter, J. Heinke, D. Gerten, and C. Piani, 2011: Impact of a statistical bias correction on the projected hydrological changes obtained from three GCMs and two hydrology models. J. Hydrometeor., 12, 556-578, https://doi.org/10.1175/2011JHM1336.1.

Hallegatte, S., 2009: Strategies to adapt to an uncertain climate change. Global Environ. Change, 19, 240-247, https://doi.org/ 10.1016/j.gloenvcha.2008.12.003.

Hawkins, E., and R. Sutton, 2011: The potential to narrow uncertainty in projections of regional precipitation change. Climate Dyn., 37, 407-418, https://doi.org/10.1007/s00382-010-0810-6.

Hay, L. E., R. L. Wilby, and G. H. Leavesley, 2000: A comparison of delta change and downscaled GCM scenarios for three mountainous basins in the United States. J. Amer. Water Resour. Assoc., 36, 387-397, https://doi.org/10.1111/j.17521688.2000.tb04276.x.

Hotelling, H., and M. R. Pabst, 1936: Rank correlation and test of significance involving no assumption of normality. Ann. Math. Stat., 7, 29-43, https://doi.org/10.1214/aoms/1177732543.

Khan, S., H. F. Gabriel, and T. Rana, 2008: Standard precipitation index to track drought and assess impact of rainfall on watertables in irrigation areas. Irrig. Drain. Syst., 22, 159-177, https://doi.org/10.1007/s10795-008-9049-3.

Kim, U., and J. J. Kaluarachchi, 2009: Climate change impacts on water resources in the upper Blue Nile River basin, Ethiopia. J. Amer. Water Resour. Assoc., 45, 1361-1378, https://doi.org/ 10.1111/j.1752-1688.2009.00369.x.

Kiparsky, M., A. Milman, and S. Vicuña, 2012: Climate and water: Knowledge of impacts to action on adaptation. Annu. Rev. Environ. Resour., 37, 163-194, https://doi.org/10.1146/ annurev-environ-050311-093931.

Lettenmaier, D. P., A. W. Wood, R. N. Palmer, E. F. Wood, and E. Z. Stakhiv, 1999: Water resources implications of global warming: A US regional perspective. Climatic Change, 43, 537-579, https://doi.org/10.1023/A:1005448007910.

Mahlstein, I., R. Knutti, S. Solomon, and R. W. Portmann, 2011: Early onset of significant local warming in low latitude countries. Environ. Res. Lett., 6, 034009, https://doi.org/10.1088/ 1748-9326/6/3/034009.

Matonse, A. H., D. C. Pierson, A. Frei, M. S. Zion, A. Anandhi, E. Schneiderman, and B. Wright, 2013: Investigating the impact of climate change on New York City's primary water supply. Climatic Change, 116, 437-456, https://doi.org/10.1007/s10584-012-0515-4.

Maurer, E. P., 2007: Uncertainty in hydrological impacts of climate change in the Sierra Nevada, California, under two emission scenarios. Climatic Change, 82, 309-325, https://doi.org/ 10.1007/s10584-006-9180-9.

, J. C. Adam, and A. W. Wood, 2009: Climate model based consensus on the hydrologic impacts of climate change to the Rio Lempa basin of central America. Hydrol. Earth Syst. Sci., 13, 183-194, https://doi.org/10.5194/hess-13-183-2009.
McKee, T. B., N. J. Doesken, and J. Kleist, 1993: The relationship of drought frequency and duration to time scale. Preprints, Eighth Conf. on Applied Climatology, Anaheim, CA, Amer. Meteor. Soc., 179-184.

Meza, F. J., D. S. Wilks, L. Gurovich, and N. Bambach, 2012: Impacts of climate change on irrigated agriculture in the Maipo Basin, Chile: Reliability of water rights and changes in the demand for irrigation. J. Water Resour. Plann. Manage., 138, 421-430, https:// doi.org/10.1061/(ASCE)WR.1943-5452.0000216.

Milly, P. C. D., J. Betancourt, M. Falkenmark, R. M. Hirsch, Z. W. Kundzewicz, D. P. Lettenmaier, and R. J. Stouffer, 2008: Stationarity is dead: Whither water management? Science, 319, 573-574, https://doi.org/10.1126/science.1151915.

— , and Coauthors, 2015: On critiques of "Stationarity is dead: Whither water management?" Water Resour. Res., 51, 77857789, https://doi.org/10.1002/2015WR017408.

Minville, M., F. Brissette, and R. Leconte, 2008: Uncertainty of the impact of climate change on the hydrology of a Nordic watershed. J. Hydrol., 358, 70-83, https://doi.org/10.1016/j.jhydrol.2008.05.033.

Mondal, M. S., and S. A. Wasimi, 2007: Evaluation of risk-related performance in water management for the Ganges Delta of Bangladesh. J. Water Resour. Plann. Manage., 133, 179-187, https://doi.org/10.1061/(ASCE)0733-9496(2007)133:2(179).

— J. U. Chowdhury, and M. R. Ferdous, 2010: Risk-based evaluation for meeting future water demand of the Brahmaputra floodplain within Bangladesh. Water Resour. Manage., 24, 853-869, https://doi.org/10.1007/s11269-009-9475-5.

Moss, R. H., and Coauthors, 2010: The next generation of scenarios for climate change research and assessment. Nature, $\mathbf{4 6 3}, 747$ 756, https://doi.org/10.1038/nature08823.

Myers, D., 1994: Spatial interpolation: An overview. Geoderma, 62, 17-28, https://doi.org/10.1016/0016-7061(94)90025-6.

Obeysekera, J., and J. D. Salas, 2014: Quantifying the uncertainty of design floods under nonstationary conditions. J. Hydrol. Eng., 19, 1438-1446, https://doi.org/10.1061/(ASCE)HE.19435584.0000931.

Ouyang, F., H. Lü, Y. Zhu, J. Zhang, Z. Yu, X. Chen, and M. Li, 2014: Uncertainty analysis of downscaling method in assessing the influence of climate change on hydrology. Stochastic Environ. Res. Risk Assess., 28, 991-1010, https://doi.org/ 10.1007/s00477-013-0796-9.

Pierce, D. W., D. R. Cayan, E. P. Maurer, J. T. Abatzoglou, and K. C. Hegewisch, 2015: Improved bias correction techniques for hydrological simulations of climate change. J. Hydrometeor., 16, 2421-2442, https://doi.org/10.1175/JHM-D-14-0236.1.

Rajagopalan, B., and U. Lall, 1999: A k-nearest neighbor simulation for daily precipitation and other weather variables. Water Resour. Res., 35, 3089-3101, https://doi.org/10.1029/1999WR900028.

Read, L. K., and R. M. Vogel, 2015: Reliability, return periods, and risk under nonstationarity. Water Resour. Res., 51, 6381-6398, https://doi.org/10.1002/2015WR017089.

Rosenblüth, B., H. A. Fuenzalida, and P. Aceituno, 1997: Recent temperature variations southern South America. Int. J. Climatol., 17, 67-85, https://doi.org/10.1002/(SICI)10970088(199701)17:1<67::AID-JOC120>3.0.CO;2-G.

Salas, J. D., and J. Obeysekera, 2014: Revisiting the concepts of return period and risk for nonstationary hydrologic extreme events. J. Hydrol. Eng., 19, 554-568, https://doi.org/10.1061/ (ASCE)HE.1943-5584.0000820.

_ B. Rajagopalan, L. Saito, and C. Brown, 2012: Special section on climate change and water resources: Climate nonstationarity and water resources management. J. Water Resour. Plann. Manage., 138, 385-388, https://doi.org/10.1061/(ASCE)WR.1943-5452.0000279. 
Schaefli, B., B. Hingray, and A. Musy, 2007: Climate change and hydropower production in the Swiss Alps: Quantification of potential impacts and related modelling uncertainties. Hydrol. Earth Syst. Sci., 11, 1191-1205, https://doi.org/10.5194/ hess-11-1191-2007.

Serinaldi, F., and C. G. Kilsby, 2015: Stationarity is undead: Uncertainty dominates the distribution of extremes. Adv. Water Resour., 77, 1736, https://doi.org/10.1016/j.advwatres.2014.12.013.

Sharma, D., A. D. Gupta, and M. S. Babel, 2007: Spatial disaggregation of bias-corrected GCM precipitation for improved hydrologic simulation: Ping River basin, Thailand. Hydrol. Earth Syst. Sci., 11, 1373-1390, https://doi.org/10.5194/ hess-11-1373-2007.

Shi, H., J. Chen, K. Wang, and J. Niu, 2018: A new method and a new index for identifying socioeconomic drought events under climate change: A case study of the East River basin in China. Sci. Total Environ., 616-617, 363-375, https://doi.org/10.1016/ j.scitotenv.2017.10.321.

Shortridge, J., T. Aven, and S. Guikema, 2017: Risk assessment under deep uncertainty: A methodological comparison. Reliab. Eng. Syst. Saf., 159, 12-23, https://doi.org/10.1016/ j.ress.2016.10.017.

Stedinger, J. R., and V. W. Griffis, 2011: Getting from here to where? Flood frequency analysis and climate. J. Amer. Water Resour. Assoc., 47, 506-513, https://doi.org/10.1111/j.17521688.2011.00545.x.

Taylor, K. E., R. J. Stouffer, and G. A. Meehl, 2012: An overview of CMIP5 and the experiment design. Bull. Amer. Meteor. Soc., 93, 485-498, https://doi.org/10.1175/BAMS-D-11-00094.1.

Teng, J., J. Vaze, F. H. Chiew, B. Wang, and J. M. Perraud, 2012: Estimating the relative uncertainties sourced from GCMs and hydrological models in modeling climate change impact on runoff. J. Hydrometeor., 13, 122-139, https://doi.org/10.1175/ JHM-D-11-058.1.

Thober, S., J. Mai, and M. Zink, 2014: Stochastic temporal disaggregation of monthly precipitation for regional gridded data sets. Water Resour. Res., 50, 8714-8735, https://doi.org/10.1002/ 2014WR015930.

Trenberth, K. E., 1990: Recent observed interdecadal climate change in the Northern Hemisphere. Bull. Amer. Meteor. Soc., 71, 988-993, https://doi.org/10.1175/1520-0477(1990)071<0988: ROICCI $>2.0 . \mathrm{CO} ; 2$.
- and D. P. Stepaniak, 2001: Indices of El Niño evolution. J. Climate, 14, 1697-1701, https://doi.org/10.1175/15200442(2001)014<1697:LIOENO>2.0.CO;2.

VanRheenen, N. T., A. W. Wood, R. N. Palmer, and D. P. Lettermaier, 2004: Potential implications of PCM Climate Change scenario for Sacramento-San Joaquin River basin hydrology and water resources. Climatic Change, 62, 257-281, https://doi.org/10.1023/B:CLIM.0000013686.97342.55.

Vicuña, S., R. D. Garreaud, and J. McPhee, 2011: Climate change impacts on the hydrology of a snowmelt driven basin in semiarid Chile. Climatic Change, 105, 469-488, https://doi.org/ 10.1007/s10584-010-9888-4.

— J. McPhee, and R. D. Garreaud, 2012: Agriculture vulnerability to climate change in a snowmelt-driven basin in semiarid Chile. J. Water Resour. Plann. Manage., 138, 431-441, https:// doi.org/10.1061/(ASCE)WR.1943-5452.0000202.

Vogel, R. M., C. Yaindl, and M. Walter, 2011: Nonstationarity: Flood magnification and recurrence reduction factors in the United States. J. Amer. Water Resour. Assoc., 47, 464-474, https://doi.org/10.1111/j.1752-1688.2011.00541.x.

Walton, D. B., A. Hall, N. Berg, M. Schwartz, and F. Sun, 2017: Incorporating snow albedo feedback into downscaled temperature and snow cover projections for California's Sierra Nevada. J. Climate, 30, 1417-1438, https://doi.org/10.1175/JCLI-D-16-0168.1.

Whetton, P., K. Hennessy, J. Clarke, K. Mclnnes, and D. Kent, 2012: Use of representative climate futures in impact and adaptation assessment. Climatic Change, 115, 433-442, https:// doi.org/10.1007/s10584-012-0471-z.

Wilby, R. L., and S. Dessai, 2010: Robust adaptation to climate change. Weather, 65, 180-185, https://doi.org/10.1002/wea.543.

Wood, A. W., E. P. Maurer, A. Kumar, and D. P. Lettenmaier, 2002: Long-range experimental hydrological forecasting for the eastern United States. J. Geophys. Res., 107, 4429, https:// doi.org/10.1029/2001JD000659.

_ L. R. Leung, V. Sridhar, and D. P. Lettenmaier, 2004: Hydrological implications of dynamical and statistical approaches to downscaling climate model outputs. Climatic Change, 62, 189216, https://doi.org/10.1023/B:CLIM.0000013685.99609.9e.

Yung, B. B., B. A. Tolson, and D. H. Burn, 2011: Risk assessment of a water supply system under climate variability: A stochastic approach. Can. J. Civ. Eng., 38, 252-262, https://doi.org/10.1139/ L10-132. 